Florida International University FIU Digital Commons

$11-25-2002$

\title{
The effects of government disability benefits, accessibility laws and rehabilitation on employment choices by individuals with spinal cord injuries
}

Susan M. Bell

Florida International University

DOI: $10.25148 /$ etd.FI14050485

Follow this and additional works at: https://digitalcommons.fiu.edu/etd

Part of the Economics Commons

\section{Recommended Citation}

Bell, Susan M., "The effects of government disability benefits, accessibility laws and rehabilitation on employment choices by individuals with spinal cord injuries" (2002). FIU Electronic Theses and Dissertations. 1483.

https://digitalcommons.fiu.edu/etd/1483 
FLORIDA INTERNATIONAL UNIVERSITY

Miami, Florida

THE EFFECTS OF GOVERNMENT DISABILITY BENEFITS, ACCESSIBILITY LAWS AND REHABILITATION ON EMPLOYMENT CHOICES BY INDIVIDUALS WITH SPINAL CORD INJURIES

A dissertation submitted in partial fulfillment of the requirements for the degree of DOCTOR OF PHILOSOPHY in

ECONOMICS

by

Susan M. Bell 
To: Dean Arthur W. Herriott

College of Arts and Sciences

This dissertation, written by Susan M. Bell, and entitled The Effects of Government Disability Benefits, Accessibility Laws and Rehabilitation on Employment Choices by Individuals with Spinal Cord Injuries, having been approved in respect to style and intellectual content, is referred to you for judgement.

We have read this dissertation and recommend that it be approved.

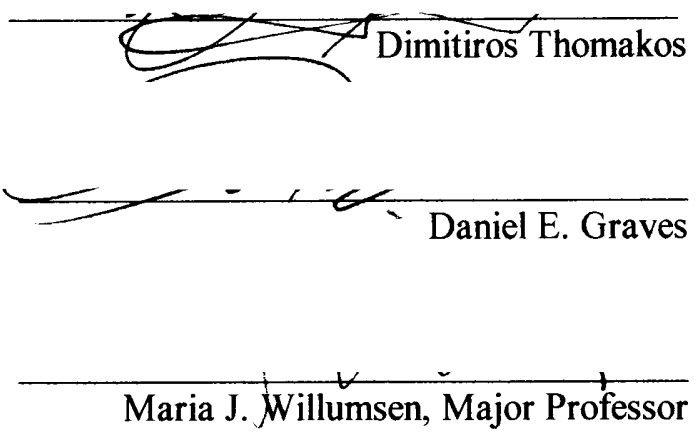

Date of Defense: November 25, 2002

The dissertation of Susan M. Bell is approved.

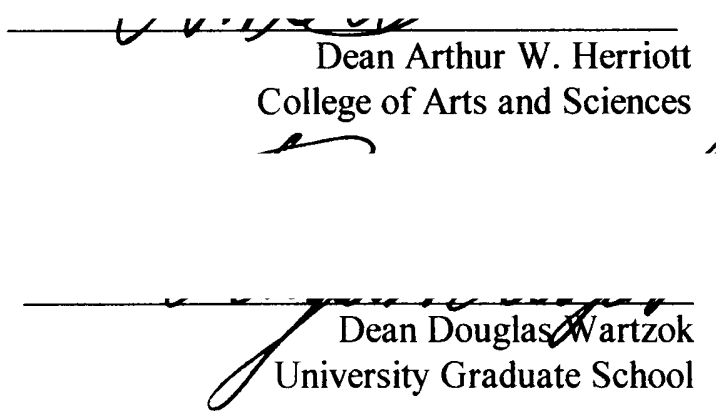

Florida International University, 2002 
(C) Copyright 2002 Susan M. Bell All rights reserved. 


\section{DEDICATION}

I dedicate this dissertation to my husband, children and parents

for their wholehearted support. 
ABSTRACT OF THE DISSERTATION

THE EFFECTS OF GOVERNMENT DISABILITY BENEFITS, ACCESSIBILITY LAWS

AND REHABILITATION ON EMPLOYMENT CHOICES BY INDIVIDUALS

WITH SPINAL CORD INJURIES

by

Susan M. Bell

Florida International University, 2002

Miami, Florida

Professor Maria J. Willumsen, Major Professor

Greater inclusion of individuals with disabilities into mainstream society is an important goal for society. One of the best ways to include individuals is to actively promote and encourage their participation in the labor force. Of all disabilities, it is feasible to assume that individual with spinal cord injuries can be among the most easily mainstreamed into the labor force. However, less that fifty percent of individuals with spinal cord injuries work.

This study focuses on how disability benefit programs, such as Social Security Disability Insurance, and Worker's Compensation, the Americans with Disabilities Act and rehabilitation programs affect employment decisions. The questions were modeled using utility theory with an augmented expenditure function and indifference theory. Statically, Probit, Logit, predicted probability, and linear regressions were used to analyze these questions. Statistical analysis was done on the probability of working, ever attempting to work after injury, and on the number of years after injury that work was first attempted and the number of hours worked per week. The data utilized were from the National Spinal Cord Injury Database and the Spinal Cord Injuries and Labor Database. The Spinal Cord Injuries and Labor Database was created specifically for this study by the author. 
Receiving disability benefits decreased the probability of working, of ever attempting to work, increased the number of years after injury before the first work attempt was made, and decreased the number of hours worked per week for those individuals working. These results were all statistically significant. The Americans with Disabilities Act decrease the number of years before an individual made a work attempt. The decrease is statistically significant. The amount of rehabilitation had a significant positive effect for male individuals with low paraplegia, and significant negative effect for individuals with high tetraplegia. For women, there were significant negative effects for high tetraplegia and high paraplegia.

This study finds that the financial disincentives of receiving benefits are the major determinants of whether an individual with a spinal cord injury returns to the labor force. Policies are recommended that would decrease the disincentive. 
INTRODUCTION

CHAPTER 1

I. Spinal Cord Injuries: Characteristics and Effects ............................................. 4

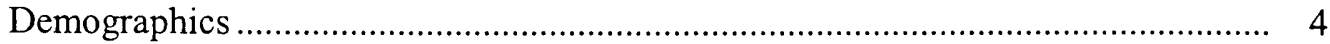

Injury Characteristics: Medical Information..................................................... 5

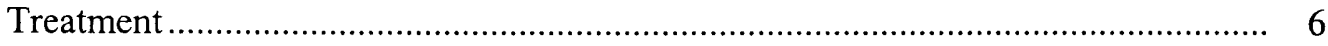

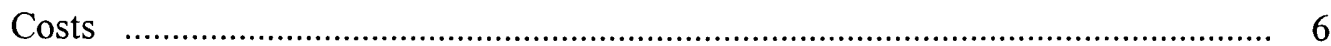

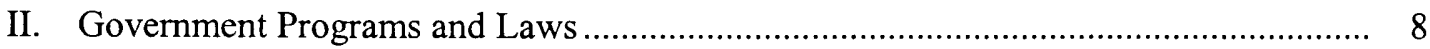

Social Security Programs .......................................................................... 9

The Americans with Disabilities Act ........................................................... 12

State Programs ............................................................................................. 15

III. Empirical Studies on Labor Force Participation by Individuals with Disabilities ........ 15

All Disabilities ........................................................................................... 15

Spinal Cord Injury Studies from the United States ........................................... 16

Spinal Cord Injury Studies from Other Countries ....................................... 17

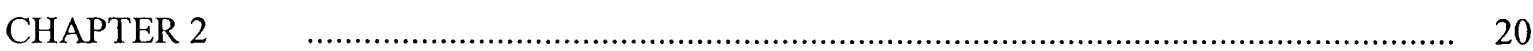

I. Mathematical Model ............................................................................ 20

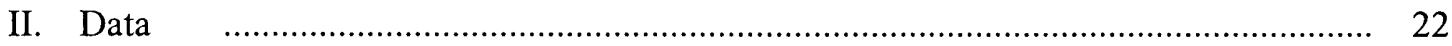

National Database ................................................................................ 22

Model and Variables ................................................................................... 23

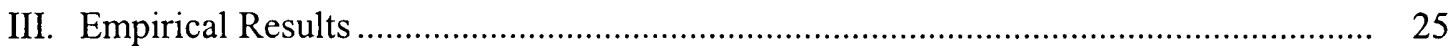

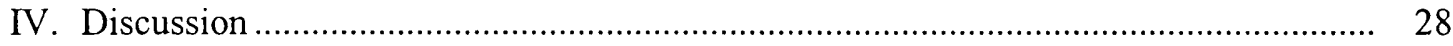

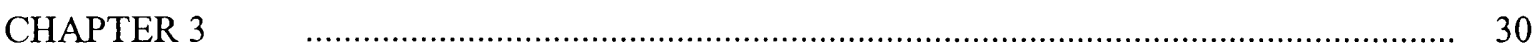

I. Theoretical Models of Effects of Earnings Limit.......................................... 32

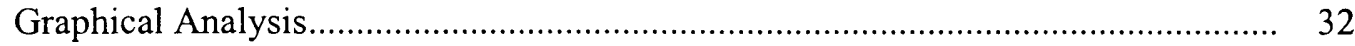

Mathematical Analysis ......................................................................... 34

II. Limitations of National Database .................................................................. 39

III. SciL Database ......................................................................................... 40

IV. Empirical Specifications ............................................................................ 47

V. Results and Discussion.......................................................................... 49

VI. Policy Implications...................................................................................... 54

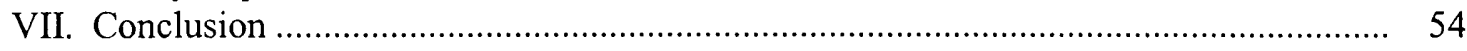

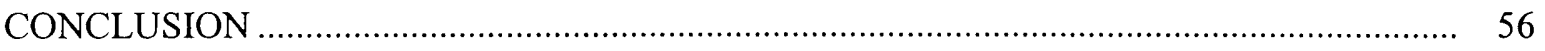

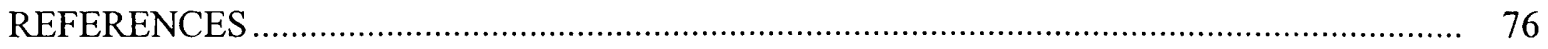

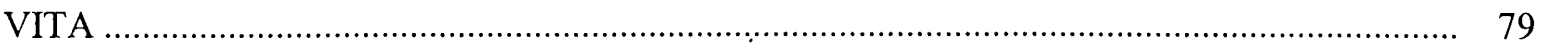




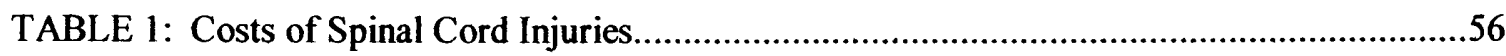

TABLE 2: Summary Statistics for National Database...........................................................57

TABLE 3: Determinants of Probability of Working after a Spinal Cord Injury............................59

TABLE 4: Determinants of Probability of Increasing Education after Injury...............................61

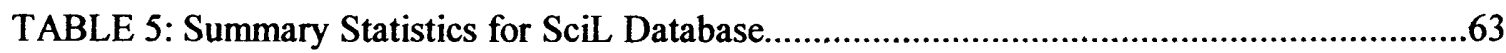

TABLE 6: Employment Rates by Gender, Education and Receipt of Disability Benefits..............65

TABLE 7: Marginal Effects on the Probability of Employment................................................66

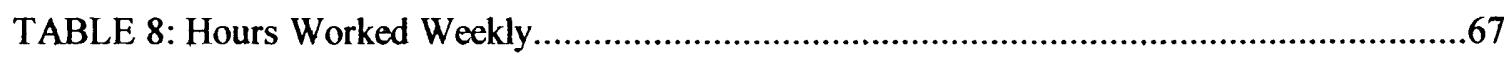

TABLE 9: Time Until First Post-Injury Attempt at Working....................................................68

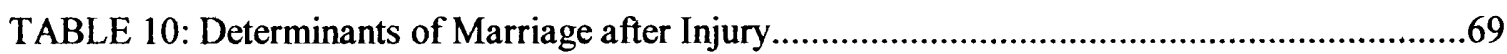




\section{LIST OF FIGURES}

FIGURE

PAGE

FIGURE 1: Possible Employment Outcomes with Benefits and Earnings Limit...........................70

FIGURE 2: The Effects of Increasing the Wage Rate on Receiving Benefits.............................71

FIGURE 3: The Effects of Decreasing Benefits on Receiving Benefits...............................72

FIGURE 4: Lowering the Marginal Tax Rate on Earned Income Over the Earnings Limit...........73

FIGURE 5: The Effect of Increasing the Earnings Limit on Labor Supplied.............................74

FIGURE 6: The Effect of Increasing Time on Labor Supplied..............................................75 


\section{INTRODUCTION:}

Greater inclusion of individuals with disabilities into mainstream society is an important goal for society. One of the best ways to include individuals is to actively promote and encourage their participation in the labor force. However, all studies find that having a disability negatively affects the probability of employment. Possible explanations include the inability to work, lack of accessibility to jobs, discrimination and financial disincentives. According to the National Institute on Disability and Rehabilitation Research, only thirty percent of individuals with disabilities work.

Of the remaining seventy percent, seventy-nine percent would like to work (Laplante et. al. 1996).

Of all disabilities, it is fair to assume that individuals with spinal cord injuries can be among the most easily mainstreamed into the labor force. An individual may have a spinal cord injury while maintaining good health, strong physical condition and intact cognitive ability and intelligence. Additionally, spinal cord injuries are non-degenerating, so the disability will not become more severe as the individual ages. Rehabilitation programs are in place to teach the information necessary for maintaining good health and the daily living skills necessary to function after injury. Accessibility issues involving individuals with SCIs tend to be straightforward and easy to address and may meet with less societal resistance. Still, less than fifty percent of individuals with spinal cord injuries work (Facts and Figures at a Glance-2001).

The focus of the paper is to determine how government and medical policies affect labor force attachment of individuals with spinal cord injuries. Studies have shown that education, race, gender and injury level all affect an individual's participation. There has also been general research done on the disincentives caused by government benefits and there is open debate on the success of the Americans with Disabilities Act in increasing employment of individuals with disabilities. Previous studies have focused on the disabled population at large, but there have been few studies that have examined the effects of rehabilitation and government programs on individuals with spinal cord 
injuries. Focusing only on individuals with spinal cord injuries eliminates some of the uncertainty in the results caused by the large variation of impact among different disabilities. Using only the injury level and completeness, which are determined by the medical community, as the measure of impairment eliminates the potential bias of self-reported disability measures.

This study deals only with individuals with spinal cord injuries to determine ways government policies and medical policy could be changed if necessary to increase the probability of employment.

Basic labor supply theory with consumption preferences and utility theory are used to model the effects of rehabilitation and government programs. The models find that disability benefits hurt the probability of an individual working. Increasing time, whether through increasing society's accessibility or through rehabilitation, increases the probability of an individual working.

To test the model two databases, the National Spinal Cord Injury Database and Spinal Cord Injury and Labor Database (SciL) are used. While the National Spinal Cord Injury database is the largest database in the United States and collects data from the major rehabilitation centers throughout the country, it does not include data on disability benefits. To counter this lack of data, I developed the second database SciL. Participants are identified through spinal cord injury support groups, wheelchair athletics, message boards and word of mouth. These methods were used to identify individuals who were not actively involved with the model centers.

Logit, Probit, predicted probability and linear regressions were used to examine the effects of rehabilitation, education, disability benefits, and the Americans with Disabilities Act on the employment and education choices of individuals with spinal cord injuries. Increasing education has significant positive effects. Using predicted probability, increasing the level of education has effects ranging from 35 to $42 \%$ for white males, 17 to 31 for black males, 26 to $30 \%$ for white females and 21 to $28 \%$ for black females. The effects of rehabilitation were mixed. The effects were positive for individuals with paraplegia and low tetraplegia, but negative for high tetraplegia. The effects were 
significant for high tetraplegia and low paraplegia. For women, all the effects were negative and they were significant for high tetraplegia and high paraplegia.

Receiving any form of disability benefits decreased the probability of working by $50 \%$. Receiving benefits decreased the probability of attempting work by a minimum of $47 \%$ and decreased the number of hours worked weekly by 14 to 21 hours. Receiving benefits also increased the number of years until a work attempt was made by approximately 2 years. However, being injured after the Americans with Disabilities Act decreased the number of years until a work attempt by 4 years. Individuals injured after the Americans with Disabilities Act was passed also expressed fewer difficulties with physical accessability and discrimination.

This work is organized as follows: chapter one explains the nature of spinal cord injuries, their costs, government programs for individuals with disabilities and previous studies in the area, chapter two analyzes the National Spinal Cord Injury Database to determine how rehabilitation and education affect an individual's choices, chapter three uses SciL to examine the effects of income transfers and accessibility laws on the employment choices by individuals with spinal cord injuries and examines how employment affects marriage choices for those individuals. 


\section{Chapter 1:}

\section{Spinal Cord Injuries: Characteristics and Effects}

\section{A. Demographics}

A spinal cord injury is defined as an injury to the spinal cord that results in neurological impairment. According to the National Spinal Cord Injury Statistical Center, the prevalence rate in the U.S. is between 183,000 and 230,000 with approximately 10,000 new cases diagnosed each year. Approximately fifty-five percent of injured individuals are between the ages of sixteen and thirty years, with the median age at injury being 31.8 years. Prior to 1990 , the average age at injury was 28.6 years; since 1990, the average has increased to 35.1 years (Facts and Figures at a Glance, 2001).

While the majority of those injured are Caucasian, this percentage has steadily decreased from greater than seventy percent in the 1970 s and 1980 s, to approximately fifty-eight percent in the 1990 s. Since minorities tend to have higher unemployment rates, as more minorities incur spinal cord injuries, the percentage of individuals with spinal cord injuries working will probably decline. Males account for approximately 80 percent of those injured, a figure that has remained constant over the decades.

Following injury, an individual's attachment to the labor force dramatically decreases.

Only thirty-five percent and twenty-four percent of individuals with paraplegia and tetraplegia ${ }^{1}$ respectively, are employed ten years after the injury occurred (Facts and Figures at a Glance, 2001). According to a study by the Paralyzed Veterans of America by Disabled Institute Studies (Disability Income Systems, 1992a, b), only fifty-one percent of individuals with spinal cord injuries has any postinjury employment experience. Similarly, Krueger and Kruse (1995) found that forty percent of individuals with SCIs in New Jersey had any post-injury employment, and only twenty-six percent ${ }^{\mathrm{I}}$ were employed full-time.

\footnotetext{
${ }^{1}$ Tetraplegia is decreased function in all four limbs. Paraplegia is decreased function in a person's legs.
} 


\section{B. Injury Characteristics: Medical Information}

The magnitude of disability a person experiences is related to the degree of neurological impairment caused by the injury. The impairment caused by a spinal cord injury depends where the injury is occurred on the spine (injury level), and the extent of disruption (the completeness) of the injury. Spinal cord injuries can be placed in two groups. Tetraplegia is a condition caused by an injury in the cervical region (neck) that affects the function in all four extremities. Paraplegia affects only the two lower extremities. Tetraplegia lowers the functional ability of an individual more than paraplegia, making a return to employment more difficult.

The extent of spinal cord damage is called the completeness of the injury. A complete injury occurs when the neural conduction of the spinal cord has been completely disrupted and the individual has no neurological function in the lower segments of the spinal cord. There are three types of incomplete injuries. The first includes individuals who retain some sensation below the injury but no motor control. The second includes individuals with some sensation and motor control below the injury level, but the motor control is not functional. The third includes individuals with functional motor control below the injury level. An individual with a incomplete injury will often have less impairment, limiting the impact of the injury level on employment.

Individuals with complete tetraplegia can be divided into two categories: those who breathe without difficulty (low tetraplegia) and those who require some form of assistance in order to breathe (high tetraplegia). It is very unusual for a person who breathes with assistance to be employed. Total independence usually occurs when individuals regain use of their hands and fingers. With total hand function, an individual does not have to rely on others for their personal care This increases the probability that an individual will engage in work. Individuals with complete paraplegia also are divided into two groups. Individuals with high paraplegia have lost control over their abdominal muscles while individuals with low paraplegia have retained control. This greatly improves balance 
and torso control and decreases the amount of time needed for daily living activities, allowing more time for participation in the labor force.

\section{Treatment}

At this time, there is no cure for a spinal cord injury. Treatment usually consists of two parts: acute care and rehabilitation. Acute care is used to stabilize the injury to the spine with surgery and/or immobilization. Rehabilitation is initiated when the individual is considered medically stable. Participation in the labor force is one of the most important long-term goals of rehabilitation (Krause, 1996). To achieve this goal, rehabilitation teaches an individual how to manage their disability. This includes physical and occupational therapy to strengthen muscles and teach new ways of performing daily living skills, wheelchair classes to teach the individual how to use a wheelchair in society, health care classes to teach the individual how to recognize or prevent medical problems, manage their bladder and bowel programs and to learn pain management. The purpose of a rehabilitation program is to maximize the functional ability of the individual which will increase the amount of time available for an individual to participate in the labor force. A lack of knowledge in any of these areas will lower functional ability and decrease participation in the labor force.

The amount of time an individual spends in primary rehabilitation centers in the U.S. has decreased from 115 days in 1974 to 44 days in 1998 (Facts and Figures at a Glance, 2001). Two explanations are generally given for this decrease; improvement in the efficiency of care and/or increases in funding limitations, primarily due to increased emphasis on controlling costs from managed care programs (Carderas and Doctor, 1998).

\section{Costs}

A spinal cord injury imposes direct and indirect costs on the injured individual. Direct costs include medical and health care expenses and increased living expenses such as wages for personal health care workers. Depending upon the severity of the injury, average direct costs for the first year 
of injury range from $\$ 549,800$ (1999 dollars) for individuals with high tetraplegia, to $\$ 200,897$ for individuals with paraplegia. Average costs in subsequent years range from $\$ 19,694$ to $\$ 94,878$ (Table 1). When an individual does not participate in the labor force these costs are usually borne by society through government programs such as Medicaid and Medicare.

Indirect costs are primarily caused by the individual not participating in the labor force. The National Spinal Cord Injury Statistical Center estimates that indirect costs, such as lost wages and fringe benefits, average $\$ 46,000$ per year. This amount varies significantly depending on the severity of injury, level of education, and pre-employment history of the individual. Haveman et al. (1999) find that the earlier an individual becomes disabled, the greater the indirect costs, as the individual loses experience-related earning growth. This has a multiple effect, as not only do the individuals lose future earnings, but their Social Security disability and retirement benefits are also lower as their previous earning history (used to compute benefits) is less than it would for someone injured at a later age.

Also important in determining the costs of a spinal cord injury is to recognize its affect on productivity. A spinal cord injury decreases the functional movement and can cause further medical problems for the injured. Both effects, therefore, can reduce an injured worker's productivity and consequently reduce the wage the individual might expect to earn in the labor market. Finally, when facing worse earning prospects (and possibly also the ability to receive a disability benefit in the absence of large earnings), individuals with injuries may find it optimal to forego participating in the formal labor market. Moreover, the amount of time (and money) necessary to prepare oneself for a job (i.e., increased transportation time, having less flexibility in dealing with medical problems, etc.) further lowers the benefits of working and makes it even that much more likely that injured individuals will not seek out employment.

Lack of accessibility in the workplace or surrounding areas can also inhibit the pursuit of employment by injured individuals. For example, not knowing for certain that a work environment will 
be conducive to the individual (e.g., by offering an accessible washroom) or that one can easily travel to the workplace (e.g., by having access to accessible public transportation and having navigable sidewalks with curb-cuts), will also lessen the likelihood of an individual with an injury simply searching for employment. Discrimination may also play a role in the employment of the disabled. Baldwin and Johnson (2000) found possible evidence of both wage and employment discrimination, particularly wage discrimination, against the disabled. They estimate that the total unexplained wage differential between non-disabled and disabled men was on the order of $\$ 11$ billion in 1990 . Of course, attributing the unexplained portion of wages to discrimination requires having fully measured all sources of productivity differences.

Anecdotally, the indirect costs associated with a spinal cord injury appear significant, as the labor force participation rate of males with a spinal cord injury between 21 and 55 years of age is under forty percent whereas over ninety percent of non-disabled men participate in the labor force (Facts and Figures at a Glance, 2001). Moreover, in addition to reduced earnings, society likely incurs large costs in terms of providing disability benefits and health care. It is not surprising, therefore, that government has passed legislation with the intent of increasing the labor force participation (and subsequent earnings) of individuals with a spinal cord injury.

\section{Governmental Programs and Laws}

In the United States, there are several government programs directed at disabled individuals, including those with a spinal cord injury. The Federal government oversees Social Security Disability Insurance and the Americans with Disabilities Act. State governments oversee Worker's Compensation and Vocational Rehabilitation programs. A primary goal of each of these programs is to increase the employment rate of individuals with disabilities. 


\section{A. Social Security Programs}

Social Security Disability programs were established to provide a safety net for individuals who became disabled and were unable to work, but were too young for retirement. Social Security disability programs cover all individuals who meet the requirements for being classified as disabled, not just spinal cord injuries. These programs provide replacement income for the individual who cannot work due to their disability. The goal of these programs is to prevent household income from falling below the poverty level. These programs have decreased the poverty rate among households headed by all disabled men, but the payments are greater for individuals who were older when they become disabled, as payments are tied to earning history (Haveman et al. 1999, 1990). This is significant, as the majority of individuals with SCIs are injured when they are relatively young and before they have had time to either qualify for disability insurance or have a work history which would enable them to qualify for large disability benefits.

There are two types of Federal benefits; Disability Insurance and Supplemental Security benefits. To receive either type of benefit, a person must sustain a disability that prevents them from performing a major life activity (e.g., seeing, hearing, walking) and must last for more than twelve months. Social Security determines if a person is disabled by reviewing medical information from the individual's physicians, detailed questionnaires about how the individual spends their day, and how they perform common daily activities such as bathing, dressing, cooking, and a personal interview. If the individual is found to be disabled, they are placed in one of two groups; possible recovery, and permanent disability. If the disability is considered permanent, the case is reviewed once every ten years to see if the individual is still eligible for disability benefits. If recovery is possible, the case is reviewed more frequently depending upon the possibility of recovery. Most spinal cord injuries satisfy the condition of inability to perform a major life activity and can be classified as a permanent injury. ${ }^{2}$

${ }^{2}$ Krueger and Kruse (1995) found that approximately $75 \%$ of the participants in their study of individuals with SCIs received some form of government transfer benefits. 
Over the past thirty years, Social Security has loosened the standards by which they determine disability, making it easier to be classified as disabled and thus eligible for disability benefits. Bound (2002) and Haveman (2000) have found that labor market participation drops for all individuals with disabilities when it becomes easier to obtain benefits.

In order for a person more than 30 years of age to receive disability insurance, they must have worked for 20 of the 40 quarters immediately preceding the disability. For a person less than 31 , the number of quarters necessary to qualify is less. For a quarter to count as worked, the individual must have earned and paid taxes on a set minimum earnings in that quarter. This minimum increases annually. In 2000 , the minimum was $\$ 780$ per quarter. The dollar amount of benefits the individual receives depends on their earning history. For an individual to receive Supplemental Security benefits (SS) they must be disabled and poor. Whether an individual is poor is determined by the Social Security Administration and is based on the number and ages of individuals in the household, the amount of household assets, and income level of the household. There are no work qualifications for SS. The maximum monthly disability benefit an individual can receive is no more than $80 \%$ of previous earnings. If a person is eligible to receive benefits from both Social Security and Worker's Compensation their combine total can still only be $80 \%$ of previous eligible earnings. The average monthly payment is $\$ 815$, while the average monthly payment to an individual with a non-working spouse caring for a child and one child is $\$ 1,360$. To ensure the safety net is not abused, however, eligibility for disability insurance requires that the individual earn no more than $\$ 780$ per month (less any income spent on medicine or medical equipment necessary to perform a job). Moreover, after earning above the limit for nine(non-consecutive) months, a person with a disability is considered to be capable of doing substantial gainful work and is determined to be ineligible to receive benefits. Once a person is declared ineligible they receive benefits for three more months, then enter an extended work period that lasts 36 months. During this period, any month the person earns less than the earnings 
limit they can receive their former benefit payment. If they stop working, they are automatically reinstated. After this period is over, the person is removed from the disability rolls and would have to reapply to again receive benefits. Thus, after adjusting for out of pocket medical expenses, the average person with a disability receives $\$ 9780$ per year in disability benefits. Supplementing this with monthly earnings of $\$ 780$, a person with a disability can receive $\$ 19,860$ per year without jeopardizing his or her future claims to disability benefits. In contrast, for a person with a disability to accept a job paying even as little as $\$ 9,800$ a year, he or she must willingly give up all future possible disability benefits.

If an individual qualifies for benefits from Social Security they are automatically enrolled in one of two government medical insurance programs. If they receive benefits under disability insurance they receive Medicare; if they receive supplement benefits they receive Medicaid. These insurance programs pay for many of the medical costs of a spinal cord injury, including personal care assistants. Since medical costs are large for injured individual (full-time personal care assistants earn approximately $\$ 30,000$ annually), the possibility of losing insurance may be a greater disincentive to working than the monetary amount received. In the late 1990s, Congress passed a law to attempt to resolve the insurance problem. The law allowed disabled individuals to buy into Medicare or Medicaid once they return to work if they were unable to get insurance through their place of employment. When the individual's earnings exceed the earnings limit and eligibility for disability benefits is revoked, however, the individual also loses access to government provided medical insurance. ${ }^{3}$

Despite tying benefits to an earnings limit which potentially offers a strong disincentive to work, Social Security is mandated by law to actively encourage employment in other ways. The most recent law was the Ticket to Work and Work Incentive Improvement Act of 1999. The stated goal of

3 In the late 1990 s, Congress passed a law to address the disincentive caused by the medical insurance programs. The law allowed disabled individuals to buy into Medicare or Medicaid once they return to work if they were unable to get insurance through their work. The cost is based on a sliding income scale. 
this act is to "assure that more Americans with disabilities have the opportunity to participate in the workforce and lessen their dependence on public benefits." These include trial work periods in which a person can "try-out" a job for up to nine months without losing their eligibility to receive future benefits, and financial incentives for vocational rehabilitation services that succeed in returning a person with a disability to the workforce (Ticket to Work program). It also mandates Social Security to expand healthcare coverage by providing premium free hospital coverage for eight and a half years after a person has returned to work. This coverage does not cover medical equipment or personal care assistants.

\section{B. The Americans with Disabilities Act}

Another major government action for disabled individuals is The Americans with Disabilities Act (ADA), signed into law in 1990. The goal of this Act is to increase participation of individuals with disabilities in both the labor force and society by increasing access to public areas (e.g., schools, stores, government buildings, etc.) and to the workplace. ADA is divided into five titles: employment, public services, public accommodations, telecommunication, and miscellaneous. Title I deals with employment, and states that businesses must provide reasonable accommodations to protect the rights of individuals with disabilities in all aspects of employment. This Title applies only to employers of fifteen or more employees. Proponents of ADA argue that such accommodations will increase labor force participation by individuals with disabilities. Opponents of ADA's employment provisions maintain that the added requirements will decrease participation by raising the cost of employing an individual with a disability above the revenue that the individual produces (Rosen,1991; Oi, 1991; Weaver, 1991).

Throughout the 1990s, the employment rate for individuals with disabilities has declined as the employment rate for individuals without disabilities has increased. DeLeire (2000) determined the probability of employment for individuals with different characteristics (e.g., education, race) and in 
varying industries (e.g., manufacturing, retail). In all areas he found a statistically significant decrease in the probability of employment of individuals with disabilities after ADA was enacted.

Because the majority of lawsuits filed under the ADA have been for wrongful termination rather than discrimination in hiring, Angrist and Anglecou (1995) theorized that the ADA was actually a form of employment protection. Therefore, the decrease in employment was not caused by increased hiring costs, but because of potential increased firing costs. Employers had to account for the possibility of being sued for discrimination under ADA if they fired an individual with a disability, for any reason. Using data from the Current Population Survey (CPS), they estimated that even after controlling for other factors such as the increase in disability benefits, ADA had a negative impact on men with disabilities between the ages of 21 and 58 , and on women with disabilities between the ages of 21 and 39, but no effect on disabled women over forty or on non-disabled individuals. Bound (2002) argued that the ADA was not the cause of decreased labor force participation; rather, the decrease was caused by loosening the eligibility requirements for Social Security Disability benefits. Loosening the requirements meant that more individuals met the criteria for being disabled and were entitled to receive benefits. This created a larger incentive to be declared disabled and not to participate in the workforce. Using data from the CPS, he estimated a near one-to-one relationship between changes in the fractions of work-aged individuals on disability insurance, and changes in the fraction of individuals in the survey who identified themselves as limited and out of work.

As government pushes for businesses to become more accessible, some disabilities likely will be viewed more positively than others. Baldwin and Johnson (2000) discuss the role of discrimination due to personal discomfort of non-disabled individuals around disabled individuals. Spinal Cord Injuries usually do not cause discomfort to non-disabled individuals, possibly due to the injury of wellknown individuals such as Christopher Reeves. Also, changes to the workplace for an individual with a $\mathrm{SCl}$ are usually well understood and relatively inexpensive. This greater acceptance could lead to 
hiring individuals with SCIs over other disabled individuals. If this is correct, the passage of the ADA would not hurt labor force participation of individuals with SCIs, even while having a negative effect on participation by individuals with other disabilities.

Another effect of the ADA that may influence labor force participation is its mandating of accommodation in public areas through Titles 2 and 3. These Titles deal with public services and public accommodations and are applied to all businesses, state, and local governments, regardless of size. As business areas become more accessible due to curb cutouts, accessible parking, and washrooms etc., the amount of time a disabled individual spends in commuting to work and doing routine tasks at their job decrease, leaving more time for actual work. Increased accessibility at educational facilities, allowing more individuals to complete more education, also may increase participation as more disabled individuals pursue an educational degree. Krause $(2000,1998,1996)$ has shown that the more education an individual with a spinal cord injury has, the more likely they are to work. ${ }^{4}$

\section{State Programs}

All states have their own disability programs. Worker's Compensation and Vocational Rehabilitation are the two most important programs. To be eligible for Worker's Compensation a person must be injured on the job. Similar to Social Security, worker's compensation provides monthly cash payments and medical insurance. It also provides in-kind assistance, such housing subsidies, and retraining costs. The amount of benefits a person obtains from Worker's Compensation programs varies from state to state and is dependent upon the individual's income at the time of the injury.

Vocational Rehabilitation programs are programs set up by individual states to specifically help people with disabilities return to work. These programs do not provide cash payments or medical

\footnotetext{
${ }^{4}$ While the effect of the ADA on employment is debatable, the social effects have been positive.
} 
insurance. They do provide assistance in obtaining more education or other forms of training. This assistance can range from help purchasing textbooks, arranging transportation to school, paying for voice activated computers and paying full or partial tuition. The amount of assistance varies across states and can depend on how successful the state judges the individual will be in returning to work.

\section{Empirical Studies on Labor Force Participation by Individuals with Disabilities}

Research that examines labor force participation by individuals with spinal cord injuries can be divided into three groups: empirical work concerning all forms of disabilities, work involving only spinal cord injuries done in the United States, and work done in other countries.

\section{A. All Disabilities:}

Haveman et al. $(1999,1990)$ tracks the economic well-being of individuals with disabilities from 1962 to 1991 using data from the Social Security Administration's New Beneficiary Survey and from the Michigan Panel Study of Income Dynamics. They find that the labor force participation rate is significantly lower for individuals with disabilities then for individuals without disabilities. Consequently, the poverty rate for individual with disabilities, and for families headed by disabled individuals, is much higher than households headed by non-disabled individuals, particularly when the individual became disabled at a young age.

Using data from the 1994 Survey of Income and Program Participation (SIPP), Hale and Hayghe (1998) examine labor market activity. They include job searching by individuals as part of labor market activity. The respondents in the survey were divided into three groups, non-disabled, moderately disabled, and severely disabled. The majority of individuals with spinal cord injuries would be classified as severely disabled because they permanently use a wheelchair or crutches. There was little difference in labor market activity between the non-disabled group and the moderately disabled. However, there were significant differences between these groups and the severely disabled group. 
Non-disabled individuals had a labor market activity rate of 84.5 percent, moderately disabled individuals had a slightly lower activity rate of 81.6 percent, while only 29.5 percent of severely disabled individuals actively participated in the labor market.

Education and gender had significant impacts on the activity rate. Labor market activity ranged from 90.2 percent for non-disabled men with less than four years of high school, to 94.6 percent for those with four years of college. The range was much greater for severely disabled men, with a low of 20.3 percent for men with less than four years of high school, to 57.7 percent for severely disabled men with four years of college. The range was even wider for severely disabled women. Severely disabled women with less than 4 years of high school had a participation rate of 14.8 percent, while women with 4 years of college had a rate of 47.8 percent.

\section{B. Spinal Cord Injury Studies from the United States}

By analyzing data from hospitals in the Southeast and Midwest, Krause et al. (1992, 1996, 1997) concluded that a spinal cord injury not only lowers the employment rate by 40 to 50 percent but that individuals with a spinal cord injury also earn 25 percent less than non-disabled individuals. Other factors found to significantly affect the employment rate were the severity and completeness of the injury, race, age, years since injury, and education. Krause found that only three percent of individuals with spinal cord injuries who had less than four years of high school were working, while over 60 percent of those with at least four years of college were employed. Krause et al. (1999) used chi-square, cross-tabs and Logit to analyze data from the National Spinal Cord database and found similar results. He also found a negative effect on employment when the injury was caused violently, especially for Caucasians. El Ghahit and Hanson (1978) found that the amount of education completed after an injury was more significant to the probability of participating in the labor force than the total amount of education. 
Frost (1993) suggested that the best way to increase labor force participation rate among individuals with spinal cord injuries was to increase their computer skills, since even individuals with tetraplegia can be taught to operate computers through adaptive equipment. Krueger and Kruse (1995) explored this idea further and found that having computer skills led to a quicker return to work, longer working hours, and higher earnings. Fewer individuals with spinal cord injuries used computers in any capacity than non-disabled individuals. Krueger and Kruse's explanation for this gap was the lower level of employment among individuals with spinal cord injuries when most computer skills were learned on the job. This is probably no longer accurate as home computer use has exploded and Vocational Rehabilitation Programs routinely supply specially designed computers to individuals with spinal cord injuries, particularly those with tetraplegia.

\section{C: Spinal Cord Injury Studies from Other Countries}

Many other countries are also researching the impact of spinal cord injuries on employment. Four studies from Australia were done by Crisp (1992), Murphey et. al. (1997), Engel et. al (1998) and Conroy and McKenna (1999). The results from these studies mirrored Krause's (1992, 1997, 2000) studies in the United States in that they found that education, level of injury and gender all were significant for labor force participation. In Conroy's study, forty-four percent of the participants currently worked and sixty-seven percent had attempted work at some time. He found that the most consistently cited reasons for not working were lack of reliable transportation and discrimination. He also found a significant negative effect from disability benefits. Engel's study found health issues to be the major reason for not working. He also documented the negative effect of benefits in his study when fifty-one percent of individuals who had never received benefits worked while only twenty-three percent of those who had received or were receiving benefits worked.

In France, Ville and Ravaud (1996) located participants through disability journals, disability support groups and word-of-mouth. The main point of their study was to determine if individuals did 
not work because they had reevaluated their ideas of productivity given their new status as disabled individuals and decided that work was not the only way to find satisfaction. While only thirty-six percent of participants in their study were working, work was still seen as very significant to life satisfaction.

Noreau et al.(1999) in Canada also looked at the idea of a productive life that did not include employment. He divided his participants into three groups based on their levels of productivity using DeJong and Hughes model of productivity which includes working, studying, home-making, volunteering, and leisure. Fifteen percent of the participants fell into the highest productivity group and forty-nine percent were in the lowest group. Self-esteem and life satisfaction were still heavily influenced by whether or not the person worked. Noreau did find that with adequate support a person with tetraplegia was as productive as a person with paraplegia.

Sioseen et al.(1990) in Sweden also used a quality of life approach instead of focusing only on employment. Sweden has an extensive society support system that encompasses medical and personal care assistants, transportation and strong accessibility laws. With this type of support, seventy percent of the participants in this study worked and work was found to be positively correlated with a high quality of life.

Dramatically different from Sweden and its strong support system is Japan. Nakajima and Honda (1983) found that only thirty percent of participants worked and only forty-two percent had ever attempted to work, one of the lowest work attempt rates reported. Of those not working fifty percent cited poor health as the reasons. Nakajima and Honda discussed Japan's lack of societal support for individuals with disabilities as a main reason for the lack of labor force participation.

Tomassen and van Asbeck(2000) from the Netherlands examined if the physical intensity of the work an individual did before they became injured had an effect on their returning to work. They found that the more strenuous the job, the less likely an individual was to return to work after injury. 
Results also showed that with retraining there is a significant increase in the number of people working. Thirty-eight percent of those who had been retrained work, while only twenty-three percent of those who had not participated in retraining worked. They also tested to see if the results from studies conducted in the United States were valid for their country. Their results agreed with the U.S. studies that showed that age when injured, the level of injury, and the amount of education completed were all significant. Dipcot (1994) in England also replicated studies from the United States and found similar results. Thirty-one percent of his participants were employed. Sixty-seven percent of the participants who had higher education degrees were employed. Physical accessibility was the biggest stated obstacle to employment for both employed and unemployed individuals. 


\section{Chapter 2:}

\section{Introduction}

Prior to World War II, individuals with spinal cord injuries died withing a few years of being injured. During WWII, the government of Great Britain asked Dr. Ludwig Guttman to create a rehabilitation program for the numerous soldiers who sustained a spinal cord injury. Guttman's program was the start of modern spinal cord injury rehabilitation. Since that time the majority of individuals who sustain an injury receive formal rehabilitation

The goal of rehabilitation is to return the individual to as normal a life as possible, for the majority of individuals that includes a return to work. Rehabilitation strives to achieve this goal by increasing individuals' functional ability. Functional ability may also be increased by improving society's accessibility or by increasing an individual's education. Previous studies have examined the effects of education, this study will also look at the effects of increasing education. Moreover, past studies have not focused on how increasing functional ability through rehabilitation affects labor force participation. This study models the employment choices of individuals with spinal cord injuries using utility theory to test if increasing the functional ability of individuals' increases the probability of employment.

\section{Mathematical Model}

An augmented linear expenditure system with two goods: consumption and leisure will be used to estimate the effects of a spinal cord injury on labor force participation, and the effects of variables that could increase labor force participation. A spinal cord injury decreases the amount of time available to an individual for labor and leisure by increasing the time needed for daily life activities such as personal maintenance, transportation, and medical care. The effect of an injury on the individual's wage profile is more ambiguous, but for simplicity, it is assumed that wage rate is 
unaffected by the injury.

Let $\mathrm{c}$ and $\mathrm{I}$ represent consumption and leisure respectively. The necessity level of consumption and leisure are denoted by $\delta$ and $\gamma$ respectively while $\alpha$ and $\beta$ are preference parameters. Utility is given by the function

$$
U(c, l)=\alpha \ln (c-\delta)+\beta \ln (l-\gamma)
$$

Thus, the marginal utilities with respect to consumption and leisure are

$$
U_{c}=\frac{\alpha}{(c-\delta)} \quad U_{l}=\frac{\beta}{(l-\gamma)}
$$

and marginal rate of substitution is

$$
M R S=\frac{\beta(c-\delta)}{\alpha(l-\gamma)}
$$

It is assumed that all individuals have some form of unearned income that is at least equal to the necessity level of consumption and that the amount of time available to an individual, after an injury $\left(T_{d}\right)$ to divide between labor and leisure is less than the amount of time available to an individual without an injury(T). $\quad T_{d}$ is a function of physical ability $(P)$. Physical ability is a function of the injury level and completeness (I), and rehabilitation (R). Physical ability is negatively correlated to injury level and completeness. The higher the injury level, the less their physical ability. Physical ability is positively correlated to the amount of rehabilitation, with an upper limit governed by injury level and completeness. The first derivative for $T_{d}$ with respect to rehabilitation is 


$$
T_{d}=f(P(R))
$$

$$
\frac{\partial T_{d}}{\partial R}=\frac{\partial T_{d}}{\partial P} \frac{\partial P}{\partial R}>0
$$

When consumption equals the amount of unearned income, all available time is used for leisure and the reservation wage is

$$
W_{\text {Res }}=\frac{\beta(d-\delta)}{\alpha(l-\gamma)} .
$$

The first derivative of the reservation wage with respect to time is

$$
\frac{\partial W_{R E S}}{\partial T}=-\frac{\beta(d-\delta)\left(T_{d}-\gamma\right)}{\alpha}<0 .
$$

Therefore, as time increases, the probability that the individual will work increases. Increasing the amount of rehabilitation and/or society's accessibility increases time available and therefore labor force participation.

\section{Data}

\section{A. National Database}

The National Spinal Cord database is managed by the University of Alabama-Birmingham (UAB). The database is funded by the Department of Education, Office of Special Education and Rehabilitative Services, National Institute for Disability Rehabilitation and Research. Individuals are included in the database if they are injured in and continue to maintain residence in a participating 
hospital's area of influence. The database includes economic data for 3007 individuals, ending in 1998. Besides economic information, data is collected on personal and injury characteristics, medical treatment, functionality, and general health measures. Summary Statistics for the variables used from the database are in Table 2.

Of the 3007 individuals approximately $75 \%$ are Caucasian, $17 \%$ African-American, $1 \%$ Native Americans, and $1 \%$ Asian. Eighty percent are male and twenty percent are female. On average, females were slightly older than males when injured (30 vs.28 years) and were also more likely to be Caucasian ( 83 vs. 79 percent). Seventeen percent of individuals had high tetraplegia, thirtyfour percent had low tetraplegia, eighteen percent had high paraplegia and thirty percent had low paraplegia. At the time of injury slightly over fifty percent of both males and females had a high school degree, and approximately nine percent of males and eleven percent of females had a college degree or higher. Post-injury, the percentage of individuals with higher education had increased to twenty-one percent of males and twenty-three percent of females. Approximately thirty-four percent of males and thirty-six percent of females completed more education, and thirty-one percent of males and twenty-nine percent of females participated in the labor force. Of those individuals with higher education, sixty-three percent worked.

\section{B. Model and Variables}

Logit regressions were run to determine what variables affected the probability of working and the probability of increasing the amount of education completed. The study focused on the effects of rehabilitation. Logit was chosen to avoid the difficulty of not knowing the amount of disability payments an individual received. Predicted probabilities of being employed were determined using the estimated coefficients from the Logit regressions and increasing the amount of rehabilitation.

The data were separated into gender groups in order to determine the effects specific to that gender. Individuals younger than or equal to fifty-five years of age at the time of injury were included 
in the analysis of completing more education. All individuals were included in the analysis for working after injury. Different age limits were used, because if an individual was older than fifty-five when injured, they most likely took early retirement. However, if an individual with an injury was working at fifty-five there is no reason to assume they automatically stopped working.

Independent variables include injury level, completeness, age at injury, age, age squared, number of years injured, race, education completed at time of injury, national unemployment rate for the last year data was collected for each individual, and the amount of rehabilitation.

For high and low tetraplegia and paraplegia, the amount and type of rehabilitation is relatively consistent. Therefore, the variable for rehabilitation is classified according to amount of rehabilitation by injury group. However, within these groups, there is a wide variety of functionality. For example, while individuals with high paraplegia and low paraplegia would use the same method for moving from a wheelchair to a car, the amount of time an individual with low paraplegia would require would be less than the amount of time required by an individual with high paraplegia. In order to capture this increase in functional ability, individual injury levels are used. Injury levels range from 1 to 30 and corresponds to the number of vertebrae starting with 1 at the base of the head. There are four levels of completeness with 1 being a complete injury and 4 representing no lasting major neurological damage.

Race is divided into Caucasian, African-American, Native American, and Asian. The individual's age and age squared divided by 100 is also included. The unemployment rates were obtained from the United States Census.

The amount of education completed by the time interviewed, and the amount of education completed at the time of injury, is divided into seven categories and ranked in ascending order: $8^{\text {th }}$ grade or less, $9^{\text {th }}$ through $11^{\text {th }}$ grade, high school, associates degree or some college, bachelors degree, masters degree, doctoral degree. 


\section{Empirical Results}

Logit regressions were run on the probability of working using personal and injury characteristics as the independent variables. For males, there were significant positive effects on the probability of working from education, age and the number of years injured. The effect from education was the strongest. There was a negative effect from all non-Caucasian race variables, but it was significant only for African-American. This is similar to the effects of race on the employment of nondisabled individuals. The unemployment rate for African-Americans is always higher than for other races. The database did not consider Hispanic to be a race. The national unemployment rate was not significant. The level of injury was positive and significant, but completeness of injury was significant only for the fourth score, where there is functional return below the injury level. The effect of rehabilitation was significant for high tetraplegia and low paraplegia. The sign was negative for high tetraplegia and positive for low tetraplegia and paraplegia. One possible explanation for the negative sign is that with the severity of injury associated with high tetraplegia and the numerous possible complications, a long hospitalization indicates medical problems, not increased training or functionality (Table 3).

For females, education had significant positive effects. For both males and females, a college degree or higher usually provides a wage greater than the reservation wage of disability benefits thereby increasing the probability of working. Unlike the effects for males, age and length of time injured were not significant. Non-Caucasian variables had the same negative effects as for males. The unemployment rate had a larger negative effect than for males; however, it was still not significant. The non-significance of the unemployment rate for both males and females probably reflects the tight labor market of the late 1990s. As the economy slows down, the effects of the national unemployment rate will likely become significant. Minority groups, which includes the disabled population, usually have greater unemployment in economic downturns than the majority groups. 
The injury level and completeness coefficients for females were not significant. The effects of rehabilitation for high tetraplegia and high paraplegia were significant and the signs on all the rehabilitation group coefficients were negative. This negative effect is unexpected and further research is needed to try to provide an explanation. A likely possibility involves women's roles in society. Antidotal evidence suggests that women prefer not to remain in the hospital, particularly if married, so a longer stay would not imply increased knowledge or skills but medical complications (Table 3).

The predicted probabilities of participating in the labor force increased significantly when education was increased. For a white male with low tetraplegia, increasing education from a high school degree to a college degree, increased the predicted probability of working by 35 percent, for a black male 17 percent, for a white female 26 percent, and for a black female 21 percent. For a white male with high paraplegia there was a 43 percent increase, for a black male a 29 percent increase, for a white female a 27 percent increase, and for a black female a 21 percent increase. The predicted probability of working increased for a white male with low paraplegia 43 percent, for a black male 31 percent, for a white female 30 percent, and for a black 28 percent when education was increased. The large increases in education's effect on participation in the workforce education is increased agrees with the result found for individuals with all types of disabilities in Hollenbeck and Kimmel (2001). The smaller increases for African-Americans and women is also consistent with their results.

The effect of rehabilitation on the predicted probability of working was not as large. For white and black males with either high school or college and tetraplegia and low paraplegia there was only a one percent change with either a decrease or an increase. For white males with either high school or college and high paraplegia, there was an approximately four percent change in the same direction as the change in the amount of rehabilitation. For black males there was a two percent change for men with only a high school education and a five percent change for men with a college degree. The change for males with high paraplegia likely reflects that they are the group that probably benefits the most 
from rehabilitation. For women the unexpected negative coefficients caused the predictive probabilities to have an inverse relationship with the change in the amount of rehabilitation.

Since education had a strong positive effect on the probability of working, logit regressions were run on the probability of increasing the amount of completed education after injury (Table 4). For both males and females, age when injured, being African-American, and the amount of education completed at the time of injury had a significant negative effect. The negative effect of age injured is important because the average age of injury is increasing. Since the majority of individuals have only a high school education when injured, the probability of their participating in the labor force decreases if their probability of completing more education decreases due to being older at the time of injury. The number of years since injury had a significant positive effect. The amount of rehabilitation had a positive effect on the probability of completing more education for females with tetraplegia and high paraplegia. There also was a positive effect for males with low tetraplegia and paraplegia. Increasing the amount of rehabilitation for females with low paraplegia had a negative effect. One possible explanation is that long hospitalizations are usually not required for injuries at this level unless there are medical complications. None of the effects were significant.

It is important to look at variables that can be affected by policy changes, such as rehabilitation, in order to determine methods that will increase participation. Having the skills and knowledge gained from rehabilitation, that increase an individual's functional ability and the time available for work are most likely an important indicator as to the probability that an individual participates in the labor force. The number of days in a rehabilitation program might not be the best measure for determining if these skills have been learned. It is, however, the only measure of rehabilitation available at the moment. 


\section{Discussion}

Since the population of individuals' with spinal cord injuries is drawn from the population at large, it is logical that the shared variables have the same directional effect on employment and on completing more education. It is also expected that the more functional limitations an injury causes, the greater the negative effect on the probability of being employed. At this time rehabilitation is the main way to reduce these personal limitations.

As managed care has become the predominant form of health care, the amount of rehabilitation paid for by insurance is being debated. Rehabilitation is an expensive medical cost that is borne primarily by the insurer. Positive benefits from rehabilitation go primarily to the injured individual and society. However, the costs of not having enough rehabilitation are borne primarily by the injured individual and society not by insurance firms. A clear understanding of the role rehabilitation plays in determining who rejoins the labor force is needed to help determine the amount of rehabilitation an individual receives. To help in this understanding better ways to measure the skills and knowledge gained in rehabilitation need to be determined.

Labor force participation is directly related to the economic well-being of individuals with spinal cord injuries, the same as for able-bodied individuals. Increased education has a significant positive effect, however, the majority of individuals are not completing the education necessary to participate in the labor force given their physical limitations. Increasing the resources to encourage more individuals to increase their education, through tuition aid, would help increase the number of individuals workings

Rehabilitation teaches living skills and medical knowledge to increase the ability of individuals to function in society, perhaps the skills necessary to succeed in school should also be taught. For example how to take notes when there is limited mobility of hands and fingers, how to provide pressure relief to prevent pressure sores without disrupting concentration on lectures etc. Policies would need 
to be adopted that mandate this type of teaching is to be covered by managed care programs. Ensuring that all individuals acquire the needed skills and education to become working members of society will lower costs for the individual, for insurance companies as people stay healthier and to society at large. 


\title{
Chapter 3:
}

\author{
"Employment is key to living life with a disability. Even if you \\ don't start out making financial headway because you lose \\ some of your government benefits, its better to have a job for \\ the challenge and social context. It's not only the money. \\ You also feel better about yourself and you're valued more. \\ It's a reason to get up in the morning"
}

Jennifer Sheeley

Former policy advisor on the

Presidential Task Force on

Employment of Adults w/ Disabilities

\section{Introduction:}

Government programs are in place to help an individual deal with the financial effects of an injury. When an individual becomes unable to work due to a disability, financial benefits are provided to ensure the individual's survival. These benefits usually include a cash payment and medical insurance. For many individuals with spinal cord injury medical insurance is the most important part of the benefits. To ensure that these programs are only used by those who truly need them, most programs have earning limits. If a person earns above these limits, it is assumed that the individual can work and is not eligible to continue to receive benefits. While ensuring the survival of the individual is most important, Social Security Administration and state worker's compensation programs also have the goal of returning as many people as possible to work. This goal often conflicts with the desire to make sure only qualified individuals receive benefits. The earnings limit often puts 
people in the position of having to choose between working and becoming worse off financially due to the lose of their benefits, working less or not working at all. This is especially true for individuals with tetraplegia who would have to earn not only enough to cover the loss of their cash payments but also their medical costs. Costs for personal care assistants alone run between $\$ 20,000$ and $\$ 30,000$ per year. The fact that government disability benefits cause a strong disincentive to work is accepted throughout the disabled community, including able-bodied individuals involved with that community; however, there has been little research that directly focused on this area. A database was created specifically to gather information about disability benefits; who received them, the amount and how they affected employment decisions. Using this newly-created database, the study attempts to fill the gap in existing literature about the effects of disability benefits on the probability of employment The database will also be used to examine how accessibility laws affected employment for individuals with spinal cord injuries. Two Probit regressions will be run on the probability of being employed at the time of the interview, one using a dummy variable for ever having received government benefits and one using ranges for the various value of the benefits. Another Probit regression will be run to determine the effects of benefits on the probability of an individual with a spinal cord injury ever having made a work attempt. Linear regressions will be run to determine if benefits increase the number of years until a work attempt is made and decrease the number of hours worked per week. A linear regression will also be used to determine if being injured after ADA affected the number of years it took to return to the workforce. 


\section{Theoretical Analysis:}

\section{A. Graphical Analysis}

Most individuals with spinal cord injuries are eligible to receive some form of disability benefits. Benefits are assumed to include medical coverage and costs of personal care assistants. The inclusion of these items means that for many individuals, especially those with tetraplegia, the amount of benefits received is substantial. When a person receives benefits they are subject to the possibility of losing them if they are deemed able to do substantial gainful work. The possibility of losing benefits causes a break in an individual's budget line distorts an individual's employment choices.

Using basic labor supply theory and consumption preferences, a graphical model of this situation can be illustrated. Preferences are assumed to be monotonic and homogenous. The budget constraint indicates the break caused by the earning limits. The slope of the budget line is the wage rate. The amount of time available to divide between leisure and labor is assumed to decrease after injury. After being injured, the individual receives disability benefits (d) that are lost after the person earns over a specific amount (x). There are four possible outcomes in this situation (Figure 1). The first is that an individual will not work at all and be at point $\mathrm{A}$ on the graph. Anyone with preferences between the horizontal axis and ray 1 will end up at point $\mathrm{A}$. The second outcome is that a person will be between points A and B. The earnings limit is not binding in this area. The individual prefers to earn less than the maximum allowed and will still receive benefits. In the third outcome, the earnings limit is binding. Preferences in this area will lead to a decline in the amount of work. Work will decline until point $\mathrm{D}$, where the utility from working and not receiving benefits is equal to the utility of receiving benefits and earning only the maximum allowed. Point D's consumption is greater than the sum of benefits and the earning limit, because in order to prefer not to receive benefits, the individual must compensate for lost leisure. The final outcome is that a person will chose not to 
receive benefits and only have earned income. Preferences between ray 3 and the vertical axis will cause an individual to be in this situation.

The size of the break caused by the loss of benefits depends on the wage rate and the amount of benefits received. The higher the wage rate, the sooner individuals will prefer to stop receiving benefits and only have earned income (Figure 2). The break between B and D1 is smaller than the break between B and D. For many individuals, the wage rate would be increased by increasing their level of education.

A second way to lessen the negative effects of the earnings limit is to lower disability benefits (Figure 3). If disability benefits are $\mathrm{d} l$ instead of $\mathrm{d}$, and the marginal rate of substitution between labor and leisure remains the same, it will take less labor to equal the sum of benefits, earning limits, and compensation for lost leisure. Preferences along Ray $3 *$ show the new dividing line between receiving benefits and not receiving benefits. This new break (B1-D1) is smaller than the original break (B-D).

A more extreme way of eliminating the distortion caused by the earnings limit would be to remove the limits and give benefits without regard to earned income. Military disability benefits follow this pattern. This is unlikely to happen, civilian disability benefits are not meant as compensation for being injured but to replace earnings lost due to the inability to work. Another extreme measure is to end benefits; however, as a society, we have decided to supply income to those unable to work.

Another way to remove the break would be to lower the marginal tax rate on earnings over the earning limit. With an earnings limit, as soon as the individual earns over this amount they lose all their benefits. This amounts to a marginal tax rate on earned income of $100 \%$. Decreasing the marginal tax rate on earned income until the individual reaches the point where the utility from having only earned income equals the utility from receiving benefits and the earnings limit amount would eliminate the break and lesson the disincentive caused by benefits. In this situation, when preferences 
are constant, the individual is never better off working less (Figure 4). Individuals with preferences anywhere between Ray 1 and the vertical axis will work an amount equal to where their indifference curve is tangent to the new budget constraint.

Changing the earnings limit will affect the number of individuals who receive benefits. As the earnings limit increases, more people will choose to keep receiving benefits by will limit their earned income (Figure 5). For example, individuals with preferences along Ray 3 , who previously had chosen to work, will now limit their earnings.

Since the injury decreases the amount of time available to divide between labor and leisure, any policy that increases available time would increase the amount of labor force participation. Government programs such as the Americans with Disabilities Act help to increase the time available to work by increasing accessibility in the workplace. Rehabilitation programs also attempt to increase work time through teaching and therapy. If the amount of time is increased, more people will participate in the labor force along every preference ray (Figure 6). As time increases from $\mathrm{T}$ to $\mathrm{T} 1$, everyone can afford more consumption and more leisure. In order to consume more, people must work more since wages and benefits have remained the same. This is acceptable because with increased time, the amount of leisure would not decrease.

\section{B. Mathematical Analysis}

An augmented linear expenditure system with two goods, consumption and leisure, will be used to estimate the possible outcomes for labor force participation when there are earning limits on disability benefits. It will also be used to estimate the effects of changing the wage rate, the earnings limit, disability benefits and time. Utility is maximized subject to income; income includes both earned income and disability benefits. The price level for consumption is assumed to be one. Preferences are assumed to homothetic and monotonic. Necessity levels for consumption and leisure are assumed to be included in individual's preferences. Furthermore, it is assumed that all non-disabled individuals 
work. The effect of an injury on the individual's wage profile is more ambiguous, but for simplicity, it is assumed that wage rate is unaffected by the injury. However the wage rate can be changed by the actions of the individual after injury, such as obtaining more education.

Let $c$ and 1 represent consumption and leisure respectively, while $\alpha$ and $\beta$ are preference parameters. $T_{d}$ represents the amount of time available to the individual after injury and it is less than the amount available before injury. Let $\mathrm{w}$ and $\mathrm{d}$ represent wages and disability benefits. The utility function and budget constraint are given by the equations;

$$
U(c, l)=\alpha \ln c+\beta \ln l .
$$

subject to

$$
w T_{d}+d=c+w l
$$

Receiving disability benefits is subject to an earnings limit $\mathrm{x}$. If an individual earns more than this limit benefits cease.

$$
\text { If } w T>x, \text { then } d=0 \text {. }
$$

Depending on a person's preferences, there are four possible results. The first possible result is that an individual will not work and their levels of consumption and leisure are

$$
c_{n}=d, \quad l_{n}=T_{d}
$$


and the reservation wage is

$$
w_{\text {res }}=\frac{\beta d}{\alpha T_{d}} .
$$

For the second result the earning limits will not affect employment decisions. The individual will work as much as they prefer, but their earned income will be less than the limit. Income will then consist of their earned income and disability benefits and their levels of consumption and leisure are given by

$$
c_{b w}=\left(\frac{\alpha}{\alpha+\beta}\right)(w T+d) ; \quad l_{b w}=\left(\frac{\beta}{\alpha+\beta}\right) T_{d}+\left(\frac{\beta}{\alpha+\beta}\right) \frac{d}{w} .
$$

In the third possible result the earnings limit will be binding and in this case, individuals will decrease work in order to retain their benefits. Levels of consumption and leisure are

$$
c_{L}=\left(\frac{\alpha}{\alpha+\beta}\right)(x+d) ; \quad l_{L}=\left(\frac{\beta}{\alpha+\beta}\right)\left(\frac{(x+d)}{w}\right)
$$

Last, the person will choose not to receive benefits and will have only earned income and consumption and leisure will be

$$
c_{w}=\left(\frac{\alpha}{\alpha+\beta}\right) w T_{d} ; \quad l_{w}=\left(\frac{\beta}{\alpha+\beta}\right) T_{d}
$$

Comparing the four situations

$$
l_{n}>l_{w b}>l_{L}>l_{w} ; \quad \quad c_{w}>c_{L}>c_{w b}>c_{n} .
$$


A person will choose not to work only when

$$
\alpha \operatorname{lnd}+\beta \ln T_{d} \geq \alpha \ln c_{w b}+\beta \ln l_{w b}
$$

A person will choose to have only earned income when

$$
\alpha \operatorname{lnc} c_{w}+\beta \ln l_{w} \geq \alpha \ln c_{L}+\beta \ln l_{L}
$$

The simplest way to measure the break in the budget line caused by the earnings limit is to examine the difference between the amount of leisure a person has when receiving benefits and earning income equal to the earnings limits and the amount of leisure when a person is not receiving benefits but is earning an amount equal to the sum of earnings limit and disability benefits $\left(l_{e}\right)$. Assuming that a person is indifferent to lost leisure and only are concerned that their level of consumption remains the same. Therefore, at $l_{e}$ a person will stop receiving benefits.

$$
\text { break }=l_{L}-l_{e}=T_{d}-\frac{x}{w}-T_{d}-\frac{x+d}{w}=\frac{d}{w}
$$

The break is affected by changing the wage rate or disability benefits

$$
\frac{\partial b r e a k}{\partial w}=-d w^{-2}<0 ; \quad \frac{\partial b r e a k}{\partial d}=\frac{1}{w}>0
$$

Increasing the wage rate will contract the break and more people will work. Increasing the disability benefit will have the opposite effect. It will widen the gap and fewer people will work. 
The effects of changing the earnings limit can be seen in the changing number of individuals who keep receiving disability benefits even while working. When the earnings limit increases, the distance between when an individual does not work and where individuals prefer to only have earned income increases and the number of individuals who work and receive benefits increases.

$$
\frac{\partial\left(l_{n}-l_{e}\right)}{\partial x}=\frac{1}{w}>0
$$

Labor force attachment is also influenced by the amount of time available. There is a negative relationship between the reservation wage and available time. Increasing time, through accessibility laws, will result in increasing employment.

$$
\frac{\partial W_{\text {Res }}}{\partial T_{d}}=-\left(\frac{\beta d}{\alpha T_{d}^{2}}\right)<0 .
$$

\section{Limitations of National Database}

In order to determine the effects of government programs on employment, it is important to have an accurate portrayal of the economic situation of individuals with $\mathrm{SCI}$, including their participation in the labor force and in government benefit programs. While the National Database is the largest available, it has several limitations. These limitations create a negative bias against reporting labor force participation. The bias is caused by the constraints on who is admitted into the database. To be include in the database an individual is required not only to obtain their rehabilitation at a model center, but also to have remained in the geographic area of that hospital. This eliminates many possible participants. Approximately thirteen percent of all individuals with SCI are included 
in the database. Several model centers, such as Magee/Thomas Jefferson in Philadelphia, are county hospitals and their clientele includes many individuals with poor employment prospects even when able-bodied.

Requiring individuals to remain in the geographic area of the model center is especially limiting, as several model centers draw their clientele from across the nation. This is especially true for centers such as Craig Rehabilitation Hospital in Englewood, Colorado. Craig has a well-founded national reputation as one of the best centers for rehabilitation, in part because of its emphasis on sports. This reputation draws patients from across the country, very few of whom remain in the area. The rejection of individuals who leave the geographic area increases the negative bias against employment because individuals who are willing to attend rehabilitation programs far from their homes are usually highly motivated. Highly motivated individuals are also more likely to work after injury. A third problem is that until the mid 1980s, in order to be in the database, a patient had to be admitted into the model center which includes an acute hospital, within forty-eight hours of injury. Many individuals who ended up at a model center did not get there until after this deadline due to the fact that they were injured far from the centers and first admitted to local emergency rooms. In the mid-1980s, this fact was recognized and the requirement was changed to admittance into a model center within sixty days of injury with no prior rehabilitation. However, people who had completed their rehabilitation programs at the model centers prior to the change are still not included in the database A more serious constraint with the database is the lack of data on disability benefits. Income transfers are known to have an effect on employment choices. As the quote at the beginning of the chapter points out, individuals often lose financially when they first give up benefits. Therefore, it is important to have information on the transfers in order to determine how effective government policies are in achieving their goal of increasing employment of individuals with disabilities. In order to correct 
these problems, a new database was created which is used to analyze the effects of government programs on labor force participation.

\section{SciL Database:}

The SciL database (spinal cord injury and labor) was created through personal interviews I did with individuals with spinal cord injuries. The interviews involved a survey developed for this study. The survey was modeled after the National Database survey and a childcare survey created by Ann Witte (1997) and organized into four sections. The first section contains questions regarding personal and injury characteristics. Participants were asked when and how they were injured, how old they were at injury, where they obtained their rehabilitation, and how much rehabilitation they received. They were asked to rate how much their own risky behavior contributed to the injury and if drugs or alcohol were involved. Questions were also asked about their family situations and their schooling history, pre and post injury. These questions were asked to determine the household that th individual with disability

The second section concentrated on employment. Questions were asked about pre-injury work experience, their current employment status and their post-injury work history. If the individual had never worked or was not currently working, they were asked to supply reasons for their nonparticipation. Participants were not asked about a specific hourly wage rate because in preliminary surveys participants either did not answer that question due to discomfort providing that information or they did not know the answer due to being salaried employees. However, a general range for wage rates can be inferred from questions about the source of their household's income. Questions were asked about any accommodations that had been made by their employer and what obstacles the participant had experienced in their work history. These questions were included to be able to analyze the Americans with Disabilities Act. 
Section three focused on activities outside employment, such as volunteer work, studying, home-making, formal participation in sports, hobbies and recreation. These questions were asked in order to judge the participant involvement in productive activities even if they were not working. The questions were based on DeJong and Hughes model of productivity. Several studies (Noreau 1999, Ville and Ravaud 1996) attempted to find measures of productivity besides labor, using adaptations of DeJong and Hughes. These questions were asked to provide data for future studies on alternative measures of productivity or life-satisfaction.

In section four, participants were asked about their financial situation, including whether they had ever received disability benefits. If they answered yes they were asked the type, Social Security Disability, Social Security Supplemental, Worker's Compensation or VA pensions and how much they received. Participants were asked if the earnings limits affected their employment decisions, and if they did, they were asked how. Questions regarding Medicare, Medicaid and personal assistants were also included in this section. This section includes the most important questions as they provide the information to be able to analyze the affect of disability benefits on employment. Questions about Medicare and other forms of medical insurance are included because they are part of the benefit payment that the individual receives.

Participants were then asked if they received private financial assistance from outside or inside their household, and if they had received any financial settlement. These conditions would lower the incentive to work Finally, participants were asked the earnings range of their household. The ranges were in increment of $\$ 15,000$ with a final range of $\$ 150,000$ and above. This was done so that upper income individuals would feel comfortable providing their income range and because after $\$ 150,000$ most financial constraints due to medical costs disappeared. The surveys were conducted by personal interview and the participants were identified through small rehabilitation centers, wheelchair sporting 
venues, private foundations that focus on spinal cord injuries, disability message boards and word of mouth. Word of mouth was used to identify and include those individuals who had returned to the able-bodied community and had little contact with any formal spinal cord injury organization. Both Crisp (1992) and Ville and Ravaud (1996) used these methods to locate participants in their studies. One problem associated with these methods was the inability to reach African-Americans. AfricanAmericans tend to be less involved in with the disabled community, so it is harder for word of mouth to be successful in reaching them. As the database continues to expand, new approaches will have to be implemented in order to find and include more African-Americans.

Concerns about selection bias were alleviated by careful examination of the sources of participants. It was determined that there was no correlation between the names an employed individual provided and the probability that those individuals would also be employed. Most people gave names of their roommates during rehabilitation.

Ninety-two individuals were contacted about participating. Of these, eighty-five individuals participated and seven declined to be in the study. This is a high response rate, reaching ninety-two percent of the identifies individuals. Surveys in most studies have a response rate between forty and seventy-five percent. The high response rate in this study can be attributed to the fact that the interviewer was identified as paraplegic at the beginning of the interview, and that the majority of participants were identified through personal contacts. During the interview participants frequently mentioned that their willingness to participate was the result of the interviewer also having a spinal cord injury. At the beginning of each potential interview, the name of the person who had provided the new contact's name and phone number was stated. The providing individual had previously given permission for their name to be released. Summary statistics are provided in Table 5 .

All, but one of the participants, identified themselves as Caucasian. Twelve percent also identified themselves as CaucasianไHispanic. The number of individuals identifying themselves as 
Hispanic is similar to the percentage in the whole population. Participants were asked how they identified themselves and were not given groupings that matched the U.S. census definitions. This was done to better reflect the participants own opinion about their race and ethnicity.

The database is sixty-seven percent male and thirty-three percent female. This differs from the percentages in most studies, including the National Spinal Cord Injury database, where males make up approximately eighty percent and females twenty percent. Arguments can be made that in most studies females are under-represented. It is likely that many women, particularly those with their own families, do not attend rehabilitation hospitals that would require separation from their families. Since there are fewer model centers, attending one may require being far from home. Therefore, women may be less likely to attend U.S. model centers or large regional or national centers.

Forty-eight percent of individuals in the SciL database have tetraplegia and fifty-two percent have paraplegia. This is similar to the percentage in the National Spinal Cord Injury database. At the time of injury, twenty-five percent were under the age of eighteen and therefore ineligible for Social Security Disability Insurance. ${ }^{5}$ Seventy-nine percent were under thirty when injured. For most participants the limited earning history caused by the young age at injury would lead to low disability payments. The majority of participants (75\%) were single when injured. At the time of the interview, thirty-three percent were married, nineteen percent were divorced and forty-seven percent were single. Approximately one-third of the participants married after being injured.

At the time of injury, sixty-four percent of the participants had less that an associate degree, while twenty-one percent had a four-year college degree or higher. Sixty percent of participants completed more education after being injured and of those forty-nine percent had received government help to increase their education level. When interviewed only forty-eight percent of individuals had less than an associates degree and fifty-two percent had a four-year degree or higher. In the SciL

\footnotetext{
${ }^{5}$ Although they would be eligible for Supplemental Social Security. A disability program based not on earnings but on total income levels below the poverty line.
} 
database, participants are better educated than in the National Database. A possible explanation of this is that individuals in the SciL database, on average, had been injured for a longer period of time While thirty-four percent of individuals in the National Database had been injured for five years or less, only fifteen percent of individuals in the SciL database had been injured for less than five years. The longer a person has been injured the more time they have had to adjust to being injured and to start and finish more education. Seventy percent of individuals whose households' yearly incomes were $\$ 15,000$ or less had no higher education. Eighty-eight percent of individuals whose household's yearly incomes were $\$ 150,000$ or above had a bachelor's degree or higher.

Seventy-five percent of the participants have at one time received government benefits. These benefits include Social Security Disability, Social Security Supplemental, Medicare, Medicaid, Worker's Compensation and military disability pensions. Sixty percent in the SciL database received benefits between $\$ 500$ and $\$ 1500$ monthly. Of the individuals who had received or were receiving benefits, sixty-three percent stated that the benefits had negatively affected their employment decisions. Twenty-nine percent said they did not work because they did not want to lose their benefits, while thirty-five percent said they had changed their amount of work because of the earnings limit.

A subset of the participants had been injured in car accidents in New Jersey when the state had a no-fault comprehensive insurance program that provided unlimited medical coverage to individuals with catastrophic injuries. There were no earning limits with this coverage. Under this program, personal care assistants for individuals with tetraplegia were provided twenty-four hours a day, seven days a week. All of the individuals who had this coverage worked. New Jersey now has a cap on medical expenses, but the individuals who were injured when there was no cap have been grandfathered in and have not lost their coverage. Other participants with tetraplegia who do not have the same amount of assistance due to financial constraints have a much smaller rate of employment. 
Since being injured, seventy-five percent of the participants have made a work attempt and fifty-four percent were working at the time of the interview. Forty-two percent of individuals with tetraplegia, and seventy percent of those with paraplegia worked. These numbers are similar to those in Conroy (1999) and Crisp (1992), but are significantly higher than the National Database's and most other studies where participants were located through hospital records. Ninety-three percent of males who had never received benefits were currently working, while only fifty-three percent of males who received benefits worked (Table 6).

Every man who had made a work attempt and had not received benefits was still working at the time of the interview. Only seventy percent of the men who had made a work attempt and did receive benefits were working. Receiving benefits hurt the labor force attachment of men. Sixty-seven percent of women who had made a work attempt and did not receive benefits were working at the time of interview. Fifty percent of the women who had received benefits were still working (Table 6).

Fifty-four percent of participants had household incomes less than $\$ 45,000$ annually, with twelve percent having incomes of less than $\$ 15,000$ annually. Thirteen percent had annual household incomes over $\$ 150,000$. Seventy-five percent of women who had household incomes less than $\$ 15,000$ annually received benefits, while only thirty-three percent of women with incomes over $\$ 150,000$ received benefits. One hundred percent of men whose incomes were less than $\$ 15,000$ annually received benefits, while only twenty-five percent of men with household incomes over $\$ 150,000$ did All males with incomes over $\$ 150,000$ were currently employed, but only seventeen percent of males with household incomes less than $\$ 15,000$ were working. Thirty-three percent of women with household incomes above $\$ 150,000$ worked, while twenty-five percent of women, who had household incomes of $\$ 15,00$ or less worked.

Among those currently not working, there was no universally report reason for not being employed. Being temporarily between jobs and health problems caused by the injury were cited as the 
main reasons. Traditional roles for women probably played a role in explaining why few married women worked. Among those individuals who have never attempted to work since being injured, financial disincentives were the most commonly cited reason. Individuals did not want to lose their disability benefits, especially the medical coverage, or considered themselves financially able to not work, primarily due to income from their disability benefits.

Participants who had work experience were asked what their biggest obstacle was while working. For those individuals who were injured and returned to work before ADA, architectural barriers and discrimination were the biggest obstacles. The largest response from those injured after ADA was that they had encountered no obstacles, followed closely by problems caused the physical challenges of the disability itself (i.e. fatigue, loss of fine motor control, etc.)

SciL is the first database to include specific information about disability benefits along with detailed information on the employment histories of the participants. This information is used to determine the effects of government programs on the probability of working after injury. Because unearned income is a known disincentive to work, testing for the probability of working without taking in the effect of receiving benefits results in a distorted outcome.

\section{IV: Empirical Specifications}

Probit regressions were estimated to ascertain the effects of disability benefits and the passage of the ADA have on the probability of employment. Probit is used because the probability of working is being tested and the marginal effects are going to be determined. For the first regression, the dependent variable was the probability of currently working. It equaled one if the individual was currently employed and zero otherwise. The explanatory variables include gender, age at injury, age at injury squared, how long a person had been injured, marital status, timing of marriage, education completed at the time of the interview, injury level, and if they had ever received any form of 
government disability benefit. A second Probit regression with the same dependent variable separated out the values of the income transfer payments into ranges to ascertain the effect of increasing the amount of benefits. A third Probit regression was run using the same explanatory variables on the probability of making a work attempt.

A linear regression was run using the number of hours worked per week as the dependent variables. Explanatory variables included gender, age at injury, age at injury squared, number of years injured, injury level, education completed at the time of interview, marital status and benefits level.

A second linear regression was run using the number of years after injury until the first work attempt as the dependent variable. The explanatory variables were gender, age at injury, age at injury squared, number of years injured, injury level, the amount of education completed at the time of injury, the marital status at the time of injury and if the injury occurred after the Americans with Disabilities Act passed. This is the only regression that compared two time periods, so it is the only one that tests for the effects of ADA.

Dummy variables were used for being married, divorced, single and if the participant married after being injured. Education was divided into four groups: high school degree or less, some college or skill training, (such as a real estate license, or stock broker certificate), bachelor's degree or an advanced degree. A dummy variable was used for receiving government benefits. Government benefits include income transfer payment and medical insurance coverage past and present. The amount of income transfers were in five ranges; zero benefits, $\$ 1-\$ 500, \$ 501-\$ 1000, \$ 1001-\$ 1500$, $\$ 1500-\$ 2000, \$ 2001$ and above. Income transfer included transfer payments to the individual with the spinal cord injury, their spouse if caring for children and their children. The variable for the amount of income transfer included the amount individuals were getting and the amount those individuals who had stopped receiving payments had been getting at the time they stopped. Injury level locates the area on the spinal cord where the injury occurred. Injury levels go from 1 to 25 . A higher 
number is an injury lower on the spinal cord causing less decrease in function. For example an individuals with an injury level of 3 has tetraplegia, while an injury level of 10 causes paraplegia. If a person was injured after ADA was enacted was used only with the linear regression for number of years before first work attempt and the number of hours worked. It was not used with the probability of being currently employed because all participants would be working under its rules.

Probit regressions were also run on the probability of getting married after injury to determine the effect employment has on individuals with spinal cord injuries attaining relationship considered routine for the able-bodied population

\section{Results and Discussion:}

Using personal, injury and economic characteristics, a Probit regression was run on the probability of working (Table 7, specification 1). Coefficients for being male, and marrying after injury for both males and females were significant at 10\%. The level of the injury, being married, and

having a bachelor's degree had coefficients that were significant at the $5 \%$. Significant at $1 \%$ were college/skill training, advanced degree and having received any amount of government assistance.

A man with a spinal cord injury had a $31 \%$ greater probability of working than a woman. This mirrors the able-bodied population where men are more likely to be in the workforce than women. For a woman getting married after being injured decreased the probability of her working by $59 \%$. For men, getting married after being injured increased the probability of working by $43 \%$

The marginal effect of increasing the injury level was approximately $3 \%$. An individual with an injury level of 20 , the most common level of paraplegia, would have an approximately $45 \%$ greater probability of working than an individual with an injury level of 5 , the most common level for tetraplegia. 
All levels of schooling produced large marginal effects. Having an advanced degree increased the probability of working by $78 \%$, a bachelors degree by $54 \%$ and some college or skill training by $77 \%$. The marginal effect for skill training was greater than for a bachelor's degree because the majority of people who had this level of education had real estate licences or brokers license, skills that were needed for jobs that are well compensated.

The marginal effect of having received or receiving any form of government assistance was $-50 \%$. Despite Social Security's stated objective of returning individuals to work, receiving any form of assistance lowered the probability of working by half. Individuals who answered that they received no income transfer payments but did receive Medicare or Medicaid were included in this variable as receiving assistance.

To analyze the effects of receiving benefits more closely a Probit regression was run on the probability of currently working separating assistance into the various levels of monthly income transfer payments(Table 7, specification 2). In the results the coefficients on injury level, skill training, bachelor's degree, and advanced degrees were significant at $1 \%$. Age at injury, age at injury squared, getting married after injury for men, and being male were significant at $5 \%$. Marriage after injury for women was significant at $10 \%$.

All, but the highest benefit level had significant negative marginal effects. Coefficients on benefit levels $1(\$ 1-\$ 500)$ and $2(\$ 501-\$ 1000)$, were significant at the $5 \%$ level. Benefit levels $3(\$ 1001-\$ 1500)$ and $4(\$ 1501-\$ 2000)$ were significant at $1 \%$ and benefit level 5 was not significant. The marginal effects of the first benefit level decreased the probability of working by $68 \%$. Individuals receiving the maximum amount of income payments at this level received only $\$ 6000$ for the year. The fact that even at this low level benefits had such a strong negative impact probably reflects the fact that these individuals would also be getting Medicare. Since benefits are based on past earnings, to receive such low benefits an individuals would have had very low earned income prior to becoming injured. 
It is likely that the person is not able to earn an income post injury that would pay enough to cover both the income transfers and medical insurance.

Benefits between $\$ 501$ and $\$ 1000$ decreased the probability of working by $61 \%$ and benefits between $\$ 1001$ and $\$ 1500$ decreased the probability by $75 \%$. Benefits over $\$ 2000$ monthly had a marginal effect of $-57 \%$, but was not significant. This is probably because to receive such a high payment their earned income before injury had to be relatively high. Therefore it is highly likely that their pre-injury job was one they could return to and make a salary high enough to cover both the potential cash payment and Medical insurance. The largest effect came with benefits between $\$ 1500$ and $\$ 2000$ monthly. The maximum payment would provide $\$ 24,000$ in yearly income. Combining this with paid medical insurance and the disincentive to work becomes extremely large. Receiving this level of benefits decreased the probability of working by $85 \%$.

Another Probit regression was run on the probability of an individual having made a work attempt(Table 7, specification 3) regardless of whether they were currently working. The amount of education was significant for all groups. Some college/skill training had a marginal effect of $8 \%$ at a significance level of $5 \%$. Both a bachelor's or advanced degree had marginal effects of $15 \%$ at $1 \%$ significance. The marginal effect of being male was $19 \%$ at $5 \%$ significance.

Only the first and fourth levels of benefits were significant. Benefit level 1 had a marginal effect of $-47 \%$ and was significant at $5 \%$. Benefit level $4(\$ 1500-\$ 2000)$ was significant at $1 \%$ and a marginal effect of $-.96 \%$. Essentially, no one who received this level of benefits tried to work. Within this sample, the majority of individuals who received this amount were single males who had previously been employed in manual labor jobs. The income they received from government benefits along with paid medical insurance appeared to be adequate for their needs and provided them with plenty of leisure, which they spent on wheelchair athletics 
To further examine the effects of government benefits a linear regression was run on the number of hours worked per week using the same explanatory variables as the first Probit regression(Table 8, specification1). Being male, having more education and receiving assistance were all significant at $1 \%$. Education increased the number of hours that a person worked, the coefficient for an advanced degree was 28 , for a bachelor's degree 23 and for some college/skill training 20 . A man would on average work 16 hours more than a woman and receiving assistance decrease the number of hours worked by $41 / 2$ hours.

A second regression was run using the income transfer levels (Table 8, specification 2). All levels of benefits decreased the number of hours worked. The second, third, and fourth levels were significant at $1 \%$. Their coefficients were $-15.884,-22.201,-26.4709$, respectively. Individuals receiving these levels of benefits essentially went from full time to part time employment. The first and fifth levels were significant at $5 \%$. The first benefit level's coefficient was -14.588 and the fifth level's was -21.8020 . The larger the benefits the greater the disincentive and the fewer hours worked.

A linear regression was run that examined the number of years till a person makes their first work attempt (Table 9). The explanatory variables were age at injury, age at injury squared, being male, injury level, the amount of education previously completed, marital status at the time of injury, if received any assistance, and if injured after ADA became law. ADA was included because one of the main issues of the Act is to improve workplace accessibility and decrease discrimination. The regression was run on a subset of the data. Only those individuals who had made a work attempt and who had been injured at 18 years old or older. Individual who had been injured when they were younger than 18 were eliminated because of the length of time before they could legally or realistically make a work attempt.

The coefficients on both skill training and bachelor's degree were significant at $5 \%$ and their coefficients were negative. They decreased the number of years till the first work attempt. This is a 
reasonable result. Having this level of education increased the chances of finding a job that would make it financially viable to stop benefits. And if the individual finished more education they took less time than someone with only a high school degree.

Assistance and ADA were both significant at 10\%. Receiving assistance increased the number of years till the first work attempt by almost $2 \frac{1}{2}$ years. Being injured after ADA decreased the number of years till the first work attempt by almost 3 year. This result, combined with participants' changing responses to their biggest employment obstacle, supports the earlier premise that ADA would help individuals with spinal cord injuries, even while there is debate over its impact on individuals with all forms of disabilities.

For men, marriage has a positive impact on the probability of employment. Why marriage would have a positive impact is not easily understood. Marriage theoretically provides a second income to support a household. Examining the database more closely found that married men worked at a much greater rate than single men (ninety-three to forty-three percent). Divorced men also worked at a greater rate than single men (seventy-five to forty-three percent). Using the timing of marriage in the regression run for the probability of working showed its significance. For men, marriage after injury had a positive employment effect. For women, it had a negative effect.

Since the timing of marriage was significant, an argument can be made that marriage does not significantly affect the probability of working, but that working significantly affects the probability of getting married after injury. A Probit regression was run to test this argument using age at injury, the number of years injured, the level of injury, the amount of education completed, government assistance, financial settlement and whether or not currently employed as independent variables. Since the criteria of marriage partners varies between men and women, separate regressions were run for each. For females, none of the variable were significant. For males, only employment was significant. The coefficient had a positive sign and was significant as the five percent level (Table 10). If a man 
was working he had a $33 \%$ greater probability of getting married. The greater probability of marrying if employed, regardless of injury level, is another argument for the importance of employment in returning individuals with spinal cord injuries to a normal life.

\section{Policy Implications}

Using the results from this study, the following policy recommendations should increase the employment rate of individuals with spinal cord injuries. Social Security, instead of guaranteeing lifetime income transfers, should pay all the costs of furthering education, up to and including doctoral programs. Receiving benefits should be contingent on attending school or active job searching. At the present time, government assistance is usually limited to arranging transportation and paying for textbooks. Without tuition assistance, the costs of furthering education is prohibitive, especially for individuals whose sole support is government benefits. Once a person had completed an agreed upon amount of education, the government would provide assistance in job searching. Benefits would be provided during a limited job search period. After that period, benefits would be provided only if there were health problems, other than having a spinal cord injury (i.e., recurrent pressure sores or bladder infections) that prevented them from working. These problems would have to be documented by a physician. The age at which injury occurred would be taken into consideration when implementing the above policy.

Medicare should provide total medical coverage, including personal health care assistants, for life. Assistants should be paid a living wage in order to ensure good and consistent care. With preventative health care, medical complications would decrease. The decrease in costs from medical complication may pay for the preventative health care. Knowing the government would be providing medical insurance for an individual with a SCI would presumably make the person a more attractive candidate for employment by lowering their costs of employment 


\section{Conclusion:}

Government benefits have strong negative effects on the participation of individuals with spinal cord injuries. They decrease the probability of working, the probability of making a work attempt, the number of hours worked weekly and they increase the number of years after injury before a person makes their first work attempt. The limited analysis of ADA showed the opposite result. ADA decreased the number of years till the first work attempt. This analysis from my own database SciL supports the model's predictions that disability benefits and the earnings limit have negative effects on employment and that government programs, such as the ADA, that increase available time by making society more accessible have positive effects.

These positive effects of ADA for individuals with spinal cord injuries were encouraging as there is debate over how successful it has been in encouraging employment. However, for individuals with spinal cord injuries, the Americans with Disabilities Act has been very successful. Wheelchair accessibility in society has increased markedly since it was passed and individuals no longer mention physical barriers and discrimination as obstacles to employment. 


\section{CONCLUSION}

Increasing the employment rate of individuals with disabilities cannot be obtained with generalized programs. Each disability presents it own challenges and needs to be studied separately in order for policies to be developed that will meet those challenges. There is strong evidence that the majority of individuals with SCI can be successfully employed and want to be employed. Men in this study who never received benefit had employment rates similar to able-bodied men. Therefore, for individuals with $\mathrm{SCI}$, specific policies could be adopted that would increase the probability of employment. Rehabilitation and education were found to be significant in increasing employment therefore education and medical costs should be covered. Rehabilitation programs should be designed that focus on getting the individual back to school and work. Research should continue on ways to measure the functional increase gained from well-designed rehabilitation programs. Increasing education should be strongly encouraged, using a carrot and stick approach. Strict time limits on benefits should be enacted, similar to restriction on welfare, this would eliminate the disincentives caused by the benefits and earnings limit. The government should also keep enforcing accessibility laws, such as ADA to continue to increase the physical accessibility of society and to increase the knowledge of the able-bodied population to combat discrimination or patronizing. Ideally, a healthy, educated individual with a SCI should be considered as competent to work as any able-bodied individual and no more eligible to receive government income transfers than a healthy individual who is able-bodied. 
Table 1: Costs of Spinal Cord Injuries

\begin{tabular}{llll}
\hline \hline $\begin{array}{l}\text { Severity of } \\
\text { Injury }\end{array}$ & Avg. st year expenses, $^{\text {expenses }}$ & $\begin{array}{l}\text { Avg. Subsequent } \\
\text { expenstimated lifetime cost when }\end{array}$ & $\begin{array}{l}\text { Es years old at injury } \\
\text { 25 }\end{array}$ \\
\hline High Tetraplegia & $\$ 549,800$ & $\$ 94,878$ & $\$ 1,713,267$ \\
Low Tetraplegia & $\$ 355,037$ & $\$ 38,685$ & $\$ 950,257$ \\
Paraplegia & $\$ 200,897$ & $\$ 19,684$ & $\$ 364,491$ \\
\hline \hline
\end{tabular}

Amounts in 1999 dollars and discounted at $2 \%$

Source: "Facts and Figures at a Glance, 2001", National Spinal Cord Statistical Center Birmingham, Alabama 
Table 2: Summary Statistics for National Database (1998)

\begin{tabular}{|c|c|c|c|c|c|c|}
\hline & unit & Total & Males & $\begin{array}{c}\text { Female } \\
\mathrm{s}\end{array}$ & $\begin{array}{c}\text { Males } \leq 55 \\
\text { at injury }\end{array}$ & $\begin{array}{c}\text { Females } 55 \\
\text { sat injury } \\
\end{array}$ \\
\hline Age at injury & $\begin{array}{l}\text { Minimum } \\
\text { Maximum } \\
\text { Mean } \\
\text { Std. dev. }\end{array}$ & $\begin{array}{l}6 \\
82 \\
29.15 \\
(12.16)\end{array}$ & $\begin{array}{l}6 \\
82 \\
28.87 \\
(11.82)\end{array}$ & $\begin{array}{l}6 \\
78 \\
30.36 \\
(13.45)\end{array}$ & $\begin{array}{l}6 \\
55 \\
27.28 \\
(9.41)\end{array}$ & $\begin{array}{l}6 \\
55 \\
28.07 \\
(10.52)\end{array}$ \\
\hline Anniversary & $\begin{array}{l}\text { Minimum } \\
\text { Maximum } \\
\text { Mean } \\
\text { Std. dev. }\end{array}$ & $\begin{array}{l}1 \\
25 \\
10.67 \\
(6.09)\end{array}$ & $\begin{array}{l}1 \\
25 \\
10.69 \\
(6.13)\end{array}$ & $\begin{array}{l}1 \\
25 \\
10.56 \\
(5.99)\end{array}$ & $\begin{array}{l}1 \\
25 \\
10.91 \\
(6.13)\end{array}$ & $\begin{array}{l}1 \\
25 \\
10.93 \\
(5.99)\end{array}$ \\
\hline Injury level & $\begin{array}{l}\text { Minimum } \\
\text { Maximum } \\
\text { Mean } \\
\text { Std. dev. }\end{array}$ & $\begin{array}{l}1 \\
30 \\
10.73 \\
(6.55)\end{array}$ & $\begin{array}{l}1 \\
30 \\
10.55 \\
(6.510\end{array}$ & $\begin{array}{l}1 \\
25 \\
11.51 \\
(5.99)\end{array}$ & $\begin{array}{l}1 \\
25 \\
10.56 \\
(6.47)\end{array}$ & $\begin{array}{l}1 \\
25 \\
11.67 \\
(6.71)\end{array}$ \\
\hline Age Now & $\begin{array}{l}\text { Minimum } \\
\text { Maximum } \\
\text { Mean } \\
\text { Std. dev. }\end{array}$ & $\begin{array}{l}18 \\
92 \\
39.82 \\
(12.23)\end{array}$ & $\begin{array}{l}18 \\
92 \\
39.56 \\
(11.96)\end{array}$ & $\begin{array}{l}19 \\
88 \\
40.93 \\
(13.24)\end{array}$ & $\begin{array}{l}18 \\
78 \\
38.19 \\
(10.27)\end{array}$ & $\begin{array}{l}19 \\
73 \\
39.00 \\
(11.04)\end{array}$ \\
\hline Race & $\begin{array}{l}\text { Minimum } \\
\text { Maximum } \\
\text { Mean } \\
\text { Std. dev. }\end{array}$ & $\begin{array}{l}1 \\
4 \\
1.23 \\
(.49)\end{array}$ & $\begin{array}{l}1 \\
4 \\
1.23 \\
(.49)\end{array}$ & $\begin{array}{l}1 \\
4 \\
1.22 \\
(.56)\end{array}$ & $\begin{array}{l}1 \\
4 \\
1.23 \\
(.49)\end{array}$ & $\begin{array}{l}1 \\
4 \\
1.2 \\
(.57)\end{array}$ \\
\hline $\begin{array}{l}\text { Education at } \\
\text { injury }\end{array}$ & $\begin{array}{l}\text { Minimum } \\
\text { Maximum } \\
\text { Mean } \\
\text { Std. dev. }\end{array}$ & $\begin{array}{l}1 \\
7 \\
2.82 \\
(1.02)\end{array}$ & $\begin{array}{l}1 \\
7 \\
2.81 \\
(1.02)\end{array}$ & $\begin{array}{l}1 \\
7 \\
2.86 \\
((1.07)\end{array}$ & $\begin{array}{l}1 \\
7 \\
2.80 \\
(.99)\end{array}$ & $\begin{array}{l}1 \\
7 \\
2.88 \\
(1.05)\end{array}$ \\
\hline $\begin{array}{l}\text { Education at } \\
\text { ann. }\end{array}$ & $\begin{array}{l}\text { Minimum } \\
\text { Maximum } \\
\text { Mean } \\
\text { Std. dev. }\end{array}$ & $\begin{array}{l}1 \\
7 \\
3.48 \\
(1.22)\end{array}$ & $\begin{array}{l}1 \\
7 \\
3.38 \\
(1.23)\end{array}$ & $\begin{array}{l}1 \\
7 \\
3.47 \\
(1.16)\end{array}$ & $\begin{array}{l}1 \\
7 \\
3.39 \\
(1.22)\end{array}$ & $\begin{array}{l}1 \\
7 \\
3.52 \\
(1.16)\end{array}$ \\
\hline $\begin{array}{l}\text { ASIA } \\
\text { (completeness) }\end{array}$ & $\begin{array}{l}\text { Minimum } \\
\text { Maximum } \\
\text { Mean } \\
\text { Std. dev. }\end{array}$ & $\begin{array}{l}1 \\
4 \\
1.91 \\
(1.19)\end{array}$ & $\begin{array}{l}1 \\
4 \\
1.88 \\
(1.17)\end{array}$ & $\begin{array}{l}1 \\
4 \\
2.05 \\
(1.25)\end{array}$ & $\begin{array}{l}1 \\
4 \\
1.83 \\
(1.15)\end{array}$ & $\begin{array}{l}1 \\
4 \\
2.01 \\
(1.24)\end{array}$ \\
\hline $\begin{array}{l}\text { Rehabilitation } \\
\text { by year }\end{array}$ & $\begin{array}{l}\text { Minimum } \\
\text { Maximum } \\
\text { Mean } \\
\text { Std. dev. }\end{array}$ & $\begin{array}{l}.01 \\
3.5 \\
.23 \\
(.14) \\
\end{array}$ & $\begin{array}{l}.01 \\
3.5 \\
.23 \\
(.1525) \\
\end{array}$ & $\begin{array}{l}.01 \\
.67 \\
.2253 \\
(.1106) \\
\end{array}$ & $\begin{array}{l}.01 \\
3.5 \\
.2344 \\
(.1534) \\
\end{array}$ & $\begin{array}{l}.01 \\
.63 \\
.23 \\
(.10) \\
\end{array}$ \\
\hline
\end{tabular}


Table 2 continued: Summary Statistics for National Database (1998)

\begin{tabular}{|c|c|c|c|c|c|c|}
\hline & unit & Total & Males & $\begin{array}{l}\text { Female } \\
\mathrm{S}\end{array}$ & $\begin{array}{l}\text { Males } \leq 55 \\
\text { at injury }\end{array}$ & $\begin{array}{l}\text { Females } 55 \\
\leq \text { at injury }\end{array}$ \\
\hline \multirow{4}{*}{$\begin{array}{l}\text { Unemployment } \\
\text { rate }\end{array}$} & Minimum & 4.2 & 4.2 & 4.2 & 4.2 & 4.2 \\
\hline & Maximum & 5.6 & 5.6 & 5.6 & 5.6 & 5.6 \\
\hline & Mean & 4.98 & 4.98 & 4.98 & 4.98 & 4.98 \\
\hline & Std. dev. & $(.42)$ & $(.42)$ & $(.42)$ & $(.42)$ & $(.42)$ \\
\hline \multirow[t]{4}{*}{$\mathrm{ADA}$} & Minimum & ----1 & 0 & 0 & 0 & 0 \\
\hline & Maximum & & 1 & 1 & 1 & 1 \\
\hline & Mean & & .38 & .40 & .37 & .37 \\
\hline & Std. dev. & & $(.48)$ & $(.49)$ & $(.48)$ & $(.48)$ \\
\hline
\end{tabular}


Table 3: Determinants of Probability of Working After a Spinal Cord Injury

\begin{tabular}{|c|c|c|}
\hline & Males & Females \\
\hline Anniversary year & $\begin{array}{l}.038^{*} \\
(.011)\end{array}$ & $\begin{array}{l}.004 \\
(.022)\end{array}$ \\
\hline Injury level & $\begin{array}{l}.057^{*} \\
(.017)\end{array}$ & $\begin{array}{l}.049 \\
(.037)\end{array}$ \\
\hline Age now & $\begin{array}{l}.106^{*} \\
(.035)\end{array}$ & $\begin{array}{l}-.0 .02 \\
(.066)\end{array}$ \\
\hline Age now squared divided by 100 & $\begin{array}{l}-.183^{*} \\
(.000)\end{array}$ & $\begin{array}{l}-.033 \\
(.078)\end{array}$ \\
\hline African-American & $\begin{array}{l}-1.174^{*} \\
(.190)\end{array}$ & $\begin{array}{l}-.566 \\
(.420)\end{array}$ \\
\hline Native American & $\begin{array}{l}-.300 \\
(.597)\end{array}$ & $\begin{array}{l}.010 \\
(.992)\end{array}$ \\
\hline Asian American & $\begin{array}{l}-.237 \\
(.587)\end{array}$ & $\begin{array}{l}-.240 \\
(.811)\end{array}$ \\
\hline $\begin{array}{l}\text { Unemployment in } \\
\text { observation year }\end{array}$ & $\begin{array}{l}-.001 \\
(.134)\end{array}$ & $\begin{array}{l}-.418 \\
(.282)\end{array}$ \\
\hline 9 th- 11 th grades & $\begin{array}{l}1.470 \\
(1.043)\end{array}$ & $\begin{array}{l}-1.482 \\
(1.520)\end{array}$ \\
\hline High school graduate & $\begin{array}{l}2.262^{*} \\
(1.023)\end{array}$ & $\begin{array}{l}1.180 \\
(1.140)\end{array}$ \\
\hline $\begin{array}{l}\text { Associates degree or } \\
\text { some college }\end{array}$ & $\begin{array}{l}3.225^{*} \\
(1.034)\end{array}$ & $\begin{array}{l}2.158 \\
(1.192)\end{array}$ \\
\hline Bachelors degree & $\begin{array}{l}4.137^{*} \\
(1.029)\end{array}$ & $\begin{array}{l}2.466^{*} \\
(1.160)\end{array}$ \\
\hline Masters degree & $\begin{array}{l}4.344^{*} \\
(1.048)\end{array}$ & $\begin{array}{l}2.879 * \\
(1.210)\end{array}$ \\
\hline Doctoral degree & $\begin{array}{l}5.058^{*} \\
(1.095)\end{array}$ & $\begin{array}{l}4.196^{*} \\
(1.661)\end{array}$ \\
\hline ASIA 2 & $\begin{array}{l}.163 \\
(.169)\end{array}$ & $\begin{array}{l}-.338 \\
(.398)\end{array}$ \\
\hline ASIA 3 & $\begin{array}{l}.135 \\
(.185)\end{array}$ & $\begin{array}{l}.380 \\
(.360)\end{array}$ \\
\hline ASIA 4 & $\begin{array}{l}.842 * \\
(.155)\end{array}$ & $\begin{array}{l}.221 \\
(.289)\end{array}$ \\
\hline
\end{tabular}

$* \mathrm{p}<.05$ 
Table 3: Determinants of Probability of Working After a Spinal Cord Injury

\begin{tabular}{lll}
\hline \hline Rehabilitation level 1 & $-.969^{*}$ & $-4.775^{*}$ \\
Rehabilitation level 2 & $(.587)$ & $(2.048)$ \\
& .459 & -1.370 \\
Rehabilitation level 3 & $(.569)$ & $(1.577)$ \\
& $2.650^{*}$ & $-3.552^{*}$ \\
Rehabilitation level 4 & $(.855)$ & $(1.962)$ \\
& .946 & -2.766 \\
Constant & $(1.099)$ & $(2.075)$ \\
& -5.818 & .908 \\
\hline \hline & $(1.446)$ & $(2.329$ \\
Nagelkerke R square & .374 & .32 \\
*p $<.05$ & & \\
\hline
\end{tabular}


Table 4: Determinants of Probability of Increasing Education after Injury

\begin{tabular}{|c|c|c|}
\hline & $\begin{array}{l}\text { Males: } 55 \text { years } \\
\text { or less at injury }\end{array}$ & $\begin{array}{c}\text { Females: } 55 \\
\text { years or less at } \\
\text { injury. }\end{array}$ \\
\hline Age injured & $\begin{array}{l}-.090 * \\
(.008)\end{array}$ & $\begin{array}{l}-.075^{*} \\
(.014)\end{array}$ \\
\hline Years injured & $\begin{array}{l}.040^{*} \\
(.015)\end{array}$ & $\begin{array}{l}.110^{*} \\
(.036)\end{array}$ \\
\hline Injury level & $\begin{array}{l}-.010 \\
(.017)\end{array}$ & $\begin{array}{l}.072 * * \\
(.040)\end{array}$ \\
\hline African-American & $\begin{array}{l}-.977^{*} \\
(.161)\end{array}$ & $\begin{array}{l}-1.135^{*} \\
(.410)\end{array}$ \\
\hline Native American & $\begin{array}{l}-.991 \\
(.606)\end{array}$ & $\begin{array}{l}-2.325^{*} \\
(.965)\end{array}$ \\
\hline Asian & $\begin{array}{l}.757 \\
(.595)\end{array}$ & $\begin{array}{l}.769 \\
(.738)\end{array}$ \\
\hline ADA & $\begin{array}{l}-.671^{*} \\
(.202)\end{array}$ & $\begin{array}{l}.359 \\
(.470)\end{array}$ \\
\hline $9^{\text {th }}$ through 12 th & $\begin{array}{l}-.335 \\
(.276)\end{array}$ & $\begin{array}{l}.227 \\
(.558)\end{array}$ \\
\hline High School degree & $\begin{array}{l}-1.691 * \\
(.270)\end{array}$ & $\begin{array}{l}-1.858 * \\
(.536)\end{array}$ \\
\hline AA degree or some college & $\begin{array}{l}-.946^{*} \\
(.451)\end{array}$ & $\begin{array}{l}-.028 \\
(1.013)\end{array}$ \\
\hline Bachelor's degree & $\begin{array}{l}-1.667^{*} \\
(.352)\end{array}$ & $\begin{array}{l}-1.907^{*} \\
(.651)\end{array}$ \\
\hline Master's degree & $\begin{array}{l}-1.586 \\
(.577)\end{array}$ & $\begin{array}{l}-7.213 \\
(11.542)\end{array}$ \\
\hline Doctorate & $\begin{array}{l}-6.120 \\
(6.463)\end{array}$ & $\begin{array}{l}-7.593 \\
(25.644)\end{array}$ \\
\hline Complete 2 & $\begin{array}{l}-.129 \\
(.172)\end{array}$ & $\begin{array}{l}-.149 \\
(.417)\end{array}$ \\
\hline Complete 3 & $\begin{array}{l}.176 \\
(.185)\end{array}$ & $\begin{array}{l}-.853 * \\
(.423)\end{array}$ \\
\hline Complete 4 & $\begin{array}{l}.139 \\
(.162) \\
\end{array}$ & $\begin{array}{l}-.362 \\
(.318) \\
\end{array}$ \\
\hline
\end{tabular}


Table 4: Determinants of Probability of Increasing Education continued.

\begin{tabular}{lll}
\hline \hline & $\begin{array}{l}\text { Males: 55 or less at } \\
\text { injury }\end{array}$ & $\begin{array}{l}\text { Females: 55 or } \\
\text { less at injury }\end{array}$ \\
\hline Amount of rehab for high tetraplegia & $\begin{array}{l}.224 \\
(.517)\end{array}$ & $\begin{array}{l}1.871 \\
(1.707)\end{array}$ \\
Amount of rehab for low tetraplegia & $\begin{array}{l}.140 \\
.548)\end{array}$ & $\begin{array}{l}1.459 \\
(1.671)\end{array}$ \\
Amount of rehab for high paraplegia & .371 & .814 \\
& $(.862)$ & $(1.959)$ \\
Amount of rehab for low paraplegia & .381 & -2.051 \\
& $(1.207)$ & $(2.177)$ \\
\hline \hline
\end{tabular}


Table 5: Summary Statistics-SciL Database

\begin{tabular}{|c|c|c|c|c|c|c|c|}
\hline & Obs. & $\mathrm{N}$ & Mean & $\begin{array}{l}\text { Std. } \\
\text { Dev. }\end{array}$ & Min. & Max. & $\begin{array}{l}\text { Employment } \\
\text { rate \% }\end{array}$ \\
\hline Age at injury & 85 & 85 & 23.67 & 8.98 & 0 & 51 & \\
\hline Age at injury squared & 85 & 85 & $\begin{array}{l}640.1 \\
2\end{array}$ & 500.42 & 0 & 2601 & \\
\hline Years injured & 85 & 85 & 16.54 & 9.65 & 2 & 54 & \\
\hline Male & 85 & 57 & .67 & .47 & 0 & 1 & 63.8 \\
\hline Female & 85 & 28 & .33 & .47 & 0 & 1 & 35.7 \\
\hline Injury Level & 85 & 85 & 10.53 & 6.14 & 3 & 24 & \\
\hline Injured after $\mathrm{ADA}$ & 85 & 29 & .34 & .48 & 0 & 1 & 60 \\
\hline Single & 85 & 41 & .48 & .50 & 0 & 1 & 42.5 \\
\hline Divorced & 85 & 16 & .19 & .39 & 0 & 1 & 62.5 \\
\hline Married & 85 & 28 & .33 & .47 & 0 & 1 & 67.9 \\
\hline Married after injury-male & 85 & 19 & .21 & .41 & 0 & 1 & 88.9 \\
\hline $\begin{array}{l}\text { Married after injury- } \\
\text { female }\end{array}$ & 85 & 8 & .09 & .29 & 0 & 1 & 37.5 \\
\hline $\begin{array}{l}\text { High school or less-pre } \\
\text { injury }\end{array}$ & 85 & 36 & .42 & .49 & 0 & 1 & \\
\hline $\begin{array}{l}\text { Some college/skill-pre } \\
\text { injury }\end{array}$ & 85 & 31 & .36 & .48 & 0 & 1 & \\
\hline $\begin{array}{l}\text { Bachelor's degree-pre } \\
\text { injury }\end{array}$ & 85 & 13 & .15 & .36 & 0 & 1 & \\
\hline Adv. degree-pre injury & 85 & 5 & .05 & .23 & 0 & 1 & \\
\hline $\begin{array}{l}\text { High school or less-post } \\
\text { injury }\end{array}$ & 85 & 8 & .09 & .29 & 0 & 1 & 12.5 \\
\hline $\begin{array}{l}\text { Some college/skill-post } \\
\text { injury }\end{array}$ & 85 & 31 & .24 & .43 & 0 & 1 & 61.3 \\
\hline $\begin{array}{l}\text { Bachelor's degree-post } \\
\text { injury }\end{array}$ & 85 & 21 & .24 & .43 & 0 & 1 & 47.6 \\
\hline Adv. degree-post injury & 85 & 46 & .29 & .45 & 0 & 1 & 56.5 \\
\hline Any gov. assistance & 85 & 63 & .74 & .44 & 0 & 1 & 46 \\
\hline
\end{tabular}


Table 5 continued.

\begin{tabular}{|c|c|c|c|c|c|c|c|}
\hline & Obs. & $\mathrm{N}$ & Mean & $\begin{array}{l}\text { Std. } \\
\text { Dev. }\end{array}$ & Min. & Max. & $\begin{array}{l}\text { Employment } \\
\text { rate } \%\end{array}$ \\
\hline Benefits per month: $\$ 0$ & 85 & 22 & .26 & .44 & 0 & 1 & 77.3 \\
\hline $\begin{array}{l}\text { Benefits per month: } \\
\$ 1-\$ 500\end{array}$ & 85 & 12 & .14 & .35 & 0 & 1 & 41.7 \\
\hline $\begin{array}{l}\text { Benefits per month: } \\
\$ 501-\$ 1000\end{array}$ & 85 & 24 & .28 & .45 & 0 & 1 & 50 \\
\hline $\begin{array}{l}\text { Benefits per month } \\
\$ 1001-\$ 1500\end{array}$ & 85 & 14 & .16 & .37 & 0 & 1 & 50 \\
\hline $\begin{array}{l}\text { Benefits per month } \\
\$ 1501-\$ 2000\end{array}$ & 85 & 7 & .08 & .27 & 0 & 1 & 14.3 \\
\hline $\begin{array}{l}\text { Benefits per month } \\
\$ 2001 \text { up }\end{array}$ & 85 & 6 & .07 & .26 & 0 & 1 & 66.7 \\
\hline Worked since injury & 85 & 65 & .75 & .43 & 0 & 1 & 71.9 \\
\hline $\begin{array}{l}\text { Years till first work } \\
\text { attempt }\end{array}$ & 59 & 65 & 4.81 & 4.85 & .1 & 22 & \\
\hline Currently employed & 85 & 47 & .54 & .50 & 0 & 1 & \\
\hline Hours worked weekly & 85 & 47 & 19.7 & 22.67 & 0 & 80 & \\
\hline
\end{tabular}


Table 6: Employment Rates by Gender, Education and Receipt of Disability Benefits

\begin{tabular}{|l|cc|cc|}
\hline & \multicolumn{2}{|c|}{ Benefits } & \multicolumn{2}{c|}{ Education } \\
& Never Received & Has Received & Less than B.A. & B.A. or higher \\
& & & & \\
\hline \hline Men & $92.9 \%$ & $53.5 \%$ & $58.6 \%$ & $67.9 \%$ \\
Women & $50.0 \%$ & $30.0 \%$ & $30.0 \%$ & $38.9 \%$ \\
\hline
\end{tabular}

Source: SciL database, author's calculations. 
Table 7: Marginal Effects on the Probability of Employment

\begin{tabular}{|c|c|c|c|c|c|c|}
\hline \multirow[t]{2}{*}{ Dependent Variable } & \multicolumn{2}{|c|}{$\begin{array}{c}\text { Employed Now } \\
\text { (1) }\end{array}$} & \multicolumn{2}{|c|}{$\begin{array}{c}\text { Employed Now } \\
\text { (2) }\end{array}$} & \multicolumn{2}{|c|}{$\begin{array}{l}\text { Work attempt } \\
\text { (3) }\end{array}$} \\
\hline & $\begin{array}{c}\text { Marginal } \\
\text { Effect }\end{array}$ & t-stat & $\begin{array}{c}\text { Marginal } \\
\text { Effect }\end{array}$ & t-stat & $\begin{array}{c}\text { Marginal } \\
\text { Effect }\end{array}$ & t-stat \\
\hline Age at Injury & .0500 & 1.42 & $.0727^{* *}$ & 2.04 & .0056 & .46 \\
\hline Age at Injury squared & -.0009 & -1.47 & $-.0012^{*}$ & -1.92 & -.0002 & -1.06 \\
\hline Years injured & .0047 & 0.54 & .0077 & .82 & .0030 & 1.41 \\
\hline Male & $.3132 *$ & 1.69 & $.4687^{* *}$ & 2.17 & $.2037^{* *}$ & 2.42 \\
\hline Married & $.4199^{*}$ & 1.93 & .3101 & 1.44 & .0136 & .701 \\
\hline Divorced & .2457 & 1.19 & .2631 & 1.33 & .1234 & 220 \\
\hline Male, married aft. inj. & $.4337^{*}$ & 1.72 & $.4761^{* *}$ & 1.99 & & \\
\hline Female, married aft. inj. & $-.5856^{*}$ & -1.83 & $-.6365^{*}$ & -1.79 & & \\
\hline Skill training & $.7737^{* * *}$ & 2.83 & $.7836^{* * *}$ & 2.73 & $.0973^{*}$ & .061 \\
\hline B.A. & $.5425^{* *}$ & 2.35 & $.5565^{* *}$ & 2.54 & $.1666^{* * *}$ & .004 \\
\hline Advanced Degree & $.7778^{* * *}$ & 3.29 & $.8111^{* * *}$ & 3.15 & $.1792^{* * *}$ & .003 \\
\hline Injury level & $.0277^{* *}$ & 2.26 & $.0396^{* * *}$ & 2.88 & .0043 & .185 \\
\hline Any gov. assistance & $-.5016^{* * *}$ & -3.02 & & & & \\
\hline Benefits: $\$ 1-\$ 500$ & & & $-.6883^{* *}$ & -2.32 & $-.4709^{* *}$ & .048 \\
\hline Benefits: $\$ 501-\$ 1000$ & & & $-.6181^{* *}$ & -2.46 & -.1108 & .268 \\
\hline Benefits: $\$ 1001-\$ 1500$ & & & $-.7521 * * *$ & -2.58 & -.3107 & .145 \\
\hline Benefits: $\$ 1501-\$ 2000$ & & & $-.8512^{* * *}$ & -3.38 & $-.9338 * * *$ & .010 \\
\hline Benefits: $\$ 2000$ and up & & & -.5748 & -1.46 & -.1108 & .486 \\
\hline Log-likelihood & -.32 .702 & & -27.373 & & -20.402 & \\
\hline Pseudo-r-squared & 0.4422 & & 0.5331 & & 0.5707 & \\
\hline Number of Observations & 85 & & 85 & & 85 & \\
\hline
\end{tabular}

Source: SciL Database.

Note: The table presents the marginal effects and t-statistics from a Probit regression. Marginal effects are calculated for a one unit change in the dependent variable while holding all other variables fixed at their mean value.

${ }^{*} \mathrm{p}<.1 \quad{ }^{* *} \mathrm{p}<.05 \quad * * * * \mathrm{p}<.01$ 
Table 8: Hours Worked Weekly

\begin{tabular}{|c|c|c|c|c|}
\hline Dependent Variable & \multicolumn{2}{|c|}{$\begin{array}{l}\text { Hours worked weekly } \\
\text { (1) }\end{array}$} & \multicolumn{2}{|c|}{$\begin{array}{c}\text { Hours worked weekly } \\
(2)\end{array}$} \\
\hline Age at injury & -.5000 & $(.9012)$ & -.5099 & $(.9196)$ \\
\hline Age at injury squared & .0068 & $(.0153)$ & .0071 & $(.0156)$ \\
\hline Years injured & .1515 & $(.2564)$ & .1584 & $(.2625)$ \\
\hline Male & $16.47^{* * *}$ & $(4.561)$ & $16.12^{* * *}$ & $(4.735)$ \\
\hline Injury Level & .5147 & $(.3540)$ & .4132 & $(.3792)$ \\
\hline Married & $9.053^{*}$ & $(4.773)$ & 7.636 & $(5.049)$ \\
\hline Divorced & -6.146 & $(5.690)$ & -9.832 & $(5.846)$ \\
\hline Skill training & $20.32 * *$ & $(7.738)$ & $20.11^{* *}$ & $(7.921)$ \\
\hline B.A. & $23.43 * * *$ & $(7.934)$ & $23.67 * * *$ & $(8.154)$ \\
\hline Advanced Degrees & $28.43 * * *$ & $(7.774)$ & $28.34^{* * *}$ & $(8.018)$ \\
\hline Any gov. assistance & $-4.556 * * *$ & $(1.155)$ & & \\
\hline Benefit: $\$ 1-\$ 500$ & & & $-14.59^{*}$ & $(7.390)$ \\
\hline Benefit: $\$ 501-\$ 1000$ & & & $-15.88 * * *$ & $(5.787)$ \\
\hline Benefit: $\$ 1001-\$ 1500$ & & & $-22.20 * * *$ & $(7.024)$ \\
\hline Benefit: $\$ 1501-\$ 2000$ & & & $-.26 .47 * * *$ & $(8.720)$ \\
\hline Benefit: $\$ 2001$ up & & & $-21.80 * *$ & $(9,135)$ \\
\hline Constant & -3.312 & $(16.68)$ & .6221 & $(16.50)$ \\
\hline R-squared & 0.4243 & & 0.4354 & \\
\hline Adjusted R-squared & 0.3363 & & 0.3110 & \\
\hline Number of Observations & 84 & & 84 & \\
\hline
\end{tabular}

Source: SciL Database.

Note: The table reports estimated coefficients (and standard errors) from a linear regression model. One participant in the survey indicated having worked but did not report the number of hours.

${ }^{*} \mathrm{p}<.1 \quad{ }^{* *} \mathrm{p}<.05 \quad{ }^{* * *} \mathrm{p}<.01$ 
Table 9: Time Until First Post-Injury Attempt at Working

\begin{tabular}{|c|c|c|c|c|}
\hline \multirow{2}{*}{$\begin{array}{l}\text { Dependent variable } \\
\text { Age at injury }\end{array}$} & \multicolumn{2}{|c|}{$\begin{array}{l}\text { Years till First Work Attempt } \\
\text { (1) }\end{array}$} & \multicolumn{2}{|c|}{$\begin{array}{l}\text { Years till First Work Attempt } \\
\text { (2) }\end{array}$} \\
\hline & -.0679 & $(.8034)$ & .4446 & $(.8652)$ \\
\hline Age at injury squared & .0014 & $(.0134)$ & -.0062 & $(.0144)$ \\
\hline Years injured & -.1279 & $(.1033)$ & -.0853 & $(.1143)$ \\
\hline Injury Level & .0554 & $(.1005)$ & .0993 & $(.1155)$ \\
\hline Male & 1.205 & $(1.308)$ & 1.067 & $(1.419)$ \\
\hline Married at injury & -1.105 & $(1.604)$ & -1.264 & $(1.657)$ \\
\hline Divorced at injury & -2.867 & $(2.741)$ & -3.369 & $(2.984)$ \\
\hline Some college/skill at injury & $-3.627^{* *}$ & $(1.498)$ & $-4.006^{* *}$ & $(1.632)$ \\
\hline B.A. at injury & $-3.773^{* *}$ & $(1.803)$ & $-4.789 * *$ & $(1.961)$ \\
\hline Advanced degree at injury & -1.616 & $(2.901)$ & -1.810 & $(3.184)$ \\
\hline Any gov. assistance & $2.502^{*}$ & $(1.437)$ & $\ldots \ldots$. & \\
\hline Benefit: $\$ 1-\$ 500$ & ..... & & $4.133^{*}$ & $(2.316)$ \\
\hline Benefit: $\$ 501-\$ 1000$ & $\ldots$. & & 1.570 & $(1.688)$ \\
\hline Benefit: $\$ 1001-\$ 1500$ & ..... & & $3.776^{* *}$ & $(1.749)$ \\
\hline Benefit: $\$ 1501-\$ 2000$ & $\ldots .$. & & 3.243 & $(2.621)$ \\
\hline Benefit5: $\$ 2001$ up & $\ldots .$. & & 1.197 & $(2.146)$ \\
\hline Post ADA & $-4.386^{* *}$ & $(1.985)$ & -4.190 & $(2.220)$ \\
\hline Constant & 7.818 & $(11.97)$ & -.6337 & $(13.07)$ \\
\hline R-squared & 0.4483 & & 0.5070 & \\
\hline Adjusted R-squared & 0.2414 & & 0.2253 & \\
\hline Number of Observations & 45 & & 45 & \\
\hline
\end{tabular}

Source: SciL Database.

$* \mathrm{p}<.1 \quad * * \mathrm{p}<.05 \quad * * * \mathrm{p}<.01$ 
Table 10: Determinants of marriage after injury

\begin{tabular}{lllll}
\hline & Men (SciL) & \multicolumn{3}{l}{ Women (SciL) } \\
\hline & Marginal effect & t-stat & Marginal effect & t-stat \\
Injury & -.005 & 0.36 & .002 & .25 \\
Age at injury & -.003 & -.33 & -.03 & .118 \\
Years injured & .0 .13 & 1.57 & .0008 & .11 \\
Gov. assistance & -.013 & -.09 & .052 & .30 \\
Settlement & -.15 & -.09 & -.0001 & -.03 \\
Current employment & $.33 *$ & -1.07 & -.03 & -.18 \\
Income Level & .023 & .68 & -.004 & -.1 \\
Education & -.06 & -1.43 & .03 & .59 \\
$\mathrm{n}$ & 57 & & 28 & \\
Pseudo r-squared & .25 & & .24 & \\
\hline \hline
\end{tabular}

Source: SciL Database.

Note: The table presents the marginal effects and t-statistics from a Probit regression. Marginal effects are calculated for a one unit change in the dependent variable while holding all other variables fixed at their mean value.

${ }^{*} \mathrm{p}<.1 \quad * * \mathrm{p}<.05 \quad * * * * \mathrm{p}<.01$ 


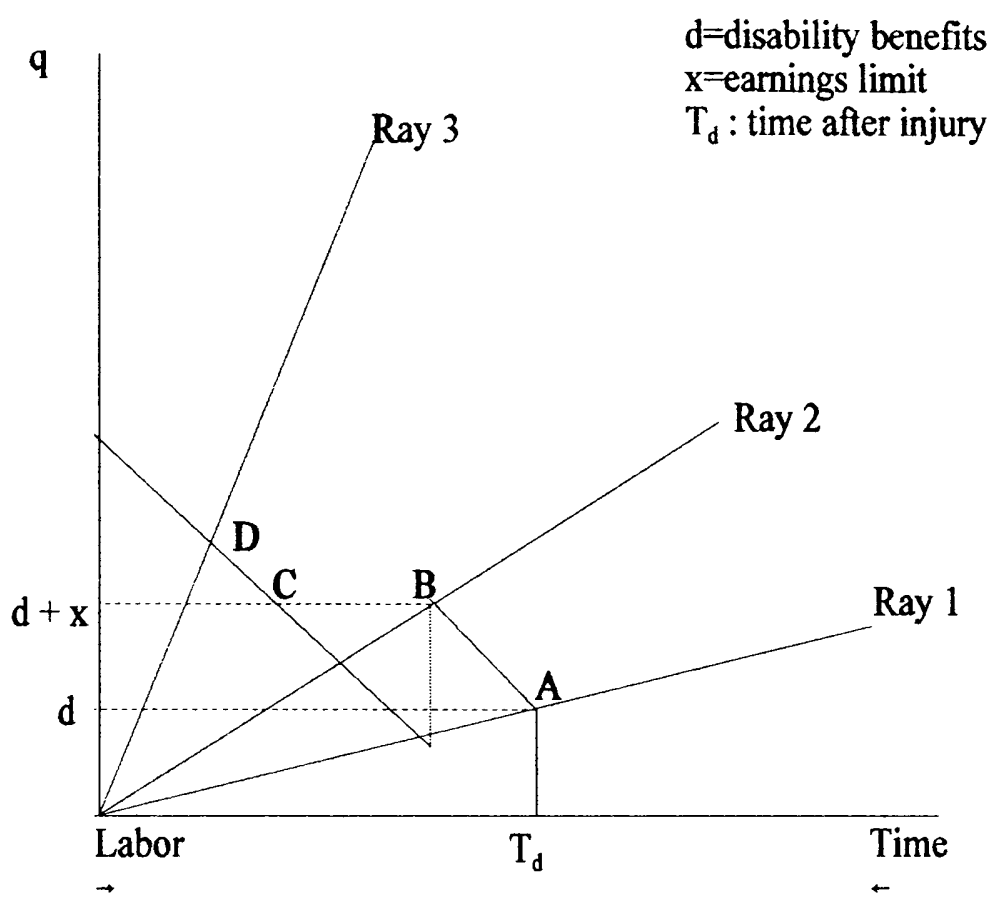

Outcome 1: An individual will not work. Preference rays between the horizontal axis and ray 1 will choose to have only their benefits as income and have all available time for leisure

Outcome 2: The earnings limit is not binding. When preference rays are between points $\mathrm{A}$ and $B$ the individual's preferred earned income is less than the earnings limit. Income will consists of their earned income and benefits.

Outcome 3: The earnings limit is binding. When preferences are between $B$ and $D$, the individual's preferred amount of labor will cause their earned income to be above the earnings limit. Point D's consumption is greater than the sum of benefits and the earning limit, because in order to prefer not to receive benefits, the individual must compensate for lost leisure. The individual will decrease their amount of labor supplied in order to avoid losing benefits and becoming worse off financially

Outcome 4: The final outcome is that a person will chose not to receive benefits and only have earned income. Preferences between ray 3 and the vertical axis will cause an individual to be in this situation 
Figure 2: The Effects of Increasing the Wage Rate on Receiving Benefits.

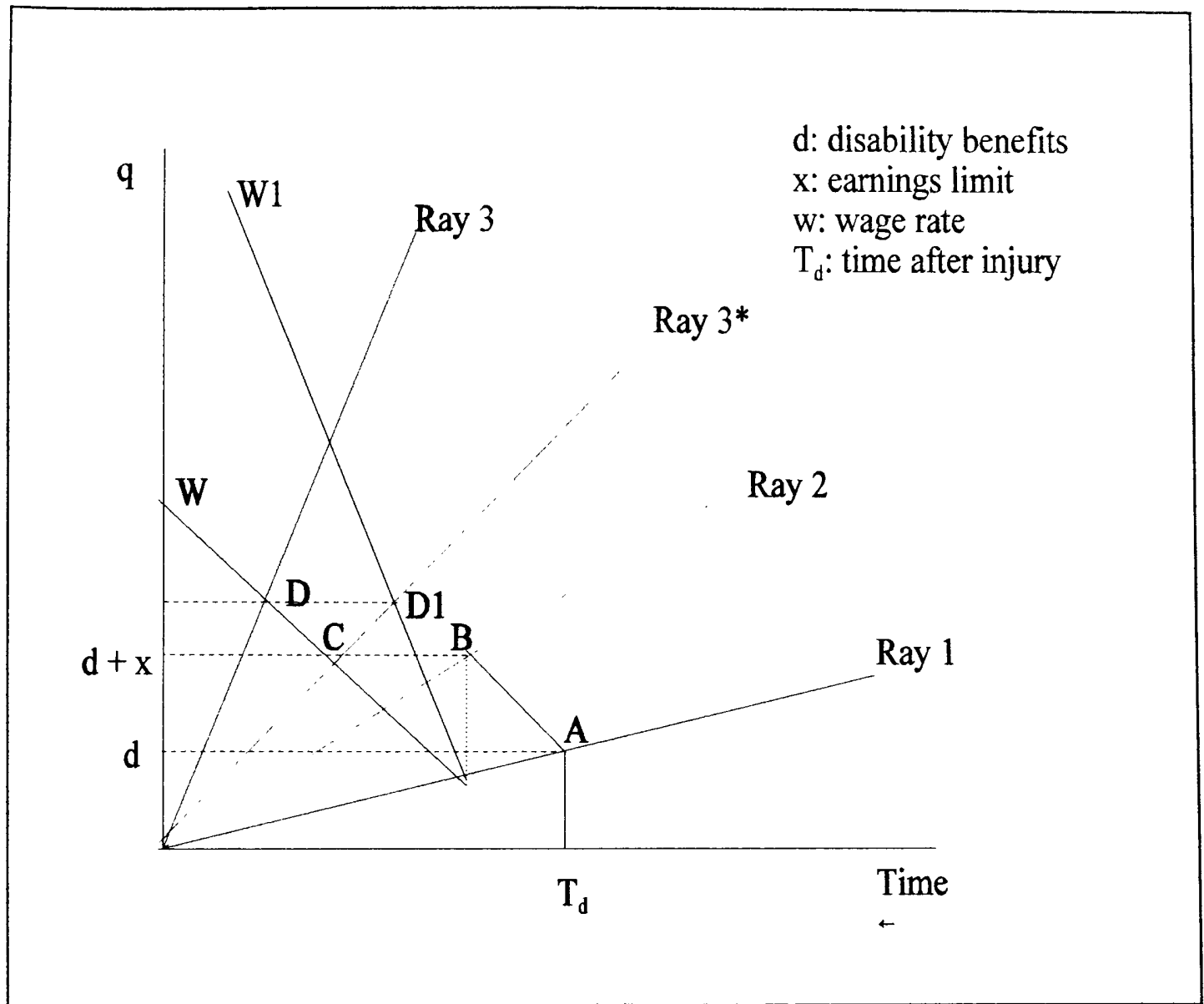

Increasing the wage rate from $\mathrm{W}$ to $\mathrm{W} 1$ will decrease the size of the break caused by the earnings limit. When the break changes from between B and D to between B and D1, individuals will reach the point where they prefer to have only earned income faster than with the original wage rate. For many individuals, the wage rate could be increased by increasing their level of education. Conversely, if the injury decreases the wage rate the size of the break will increase and an individual will find it harder to stop receiving benefits. 
Figure 3: The Effect of Decreasing Benefits on Receiving Benefits.

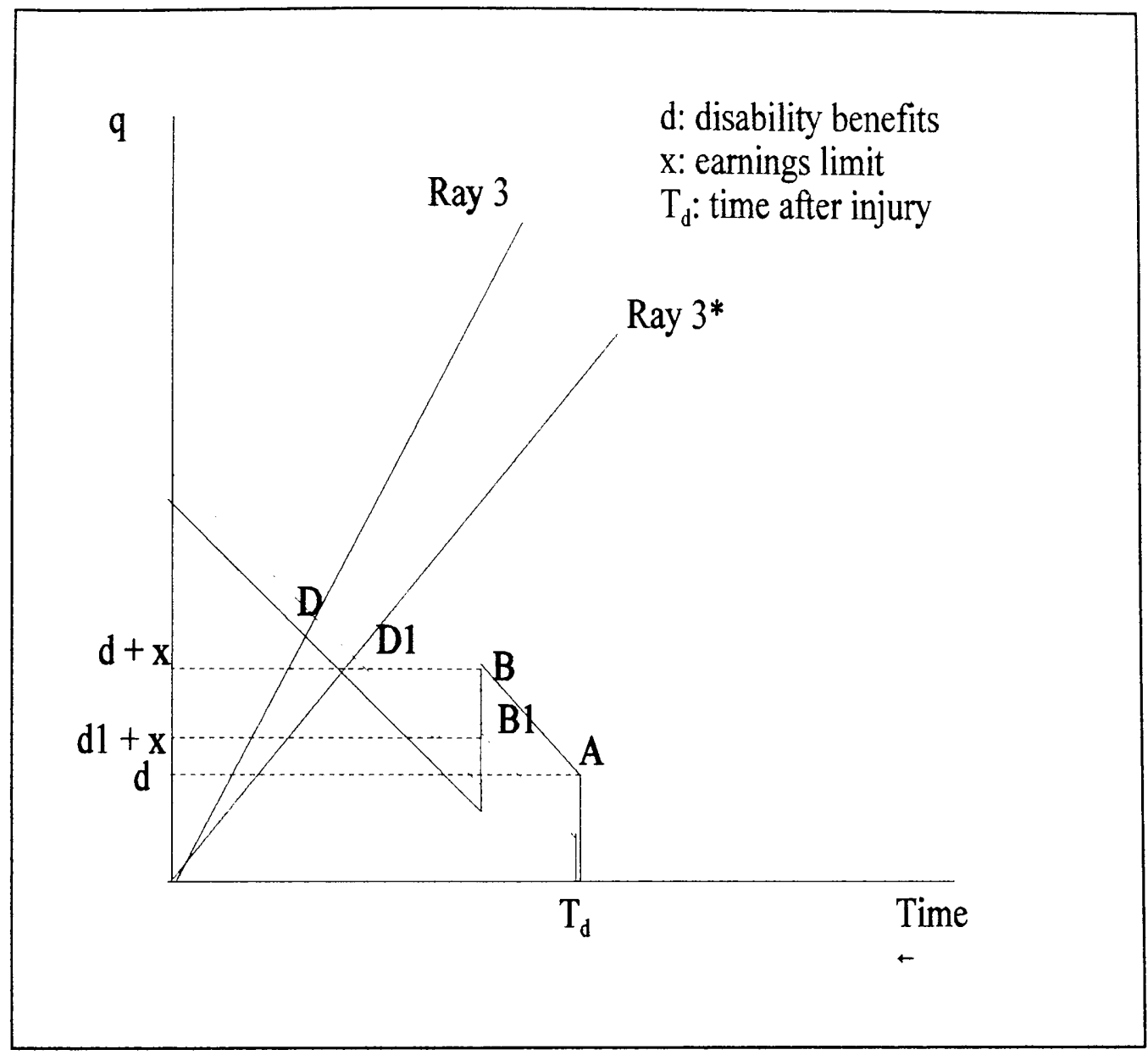

When disability benefits are $\mathrm{dl}$ instead of $\mathrm{d}$, and the marginal rate of substitution between labor and leisure remains the same, less labor will be required to earn income equal to the sum of benefits, earning limits, and compensation for lost leisure. Where Ray $3 *$ intersects the new budget line is the new point where the utility of receiving benefits equals the utility of having only earned income. This point occurs sooner with lower benefits as the individual does not have as much income to replace. Above D1 individuals will choose not to receive benefits. 
Figure 4: Lowering the Marginal Tax Rate on Earned Income over the Earnings Limit

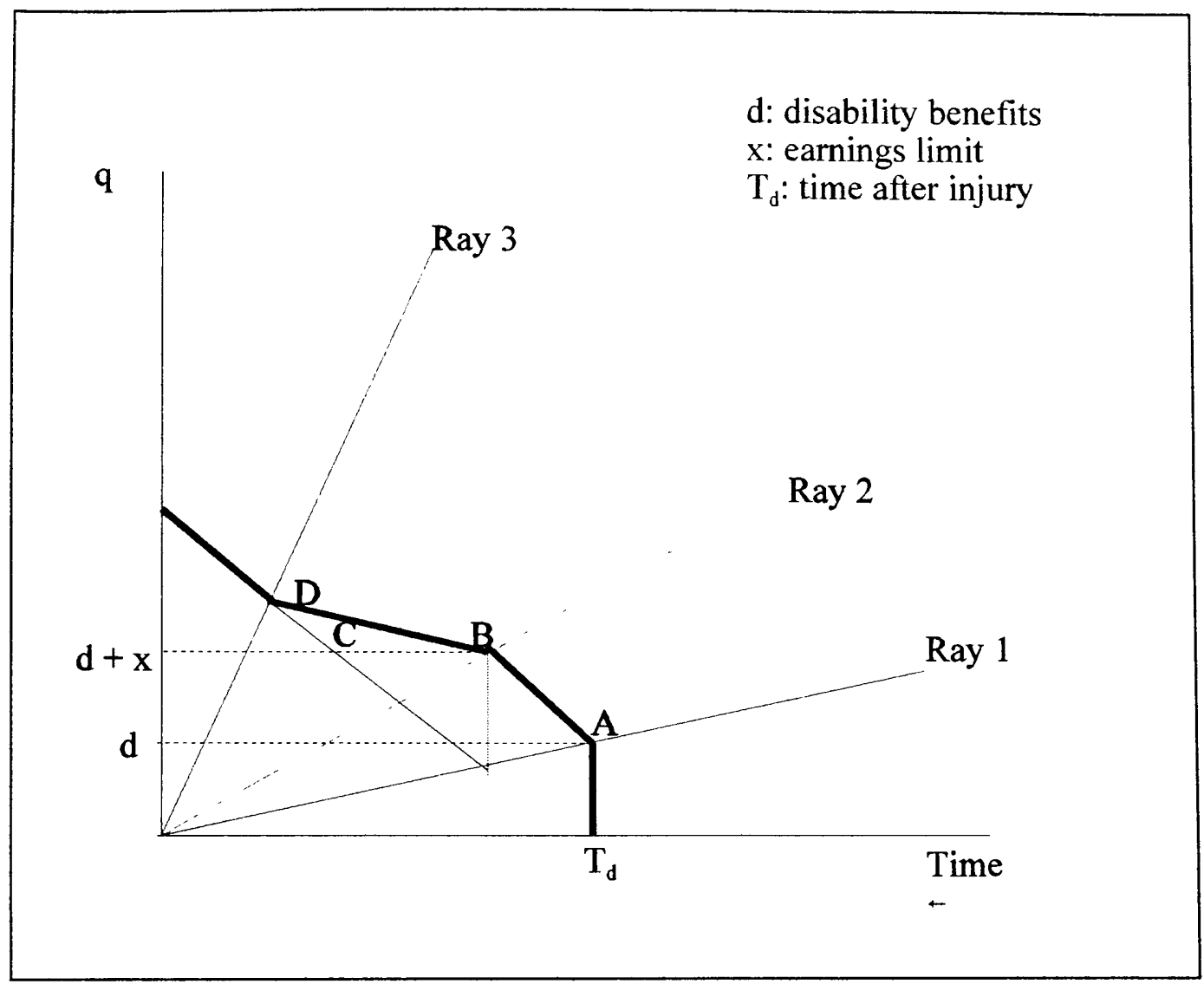

With an earnings limit, the marginal tax rate on earned income above the limit is $100 \%$.

Decreasing the marginal tax rate on earned income until the individual reaches the point where the utility from having only earned income equals the utility from receiving benefits and the earnings limit amount would eliminate the break and lesson the disincentive caused by benefits. In this situation, when preferences are constant, the individual is never better off working less. 
Figure 5: The Effect of Increasing the Earnings Limit on Labor Supplied

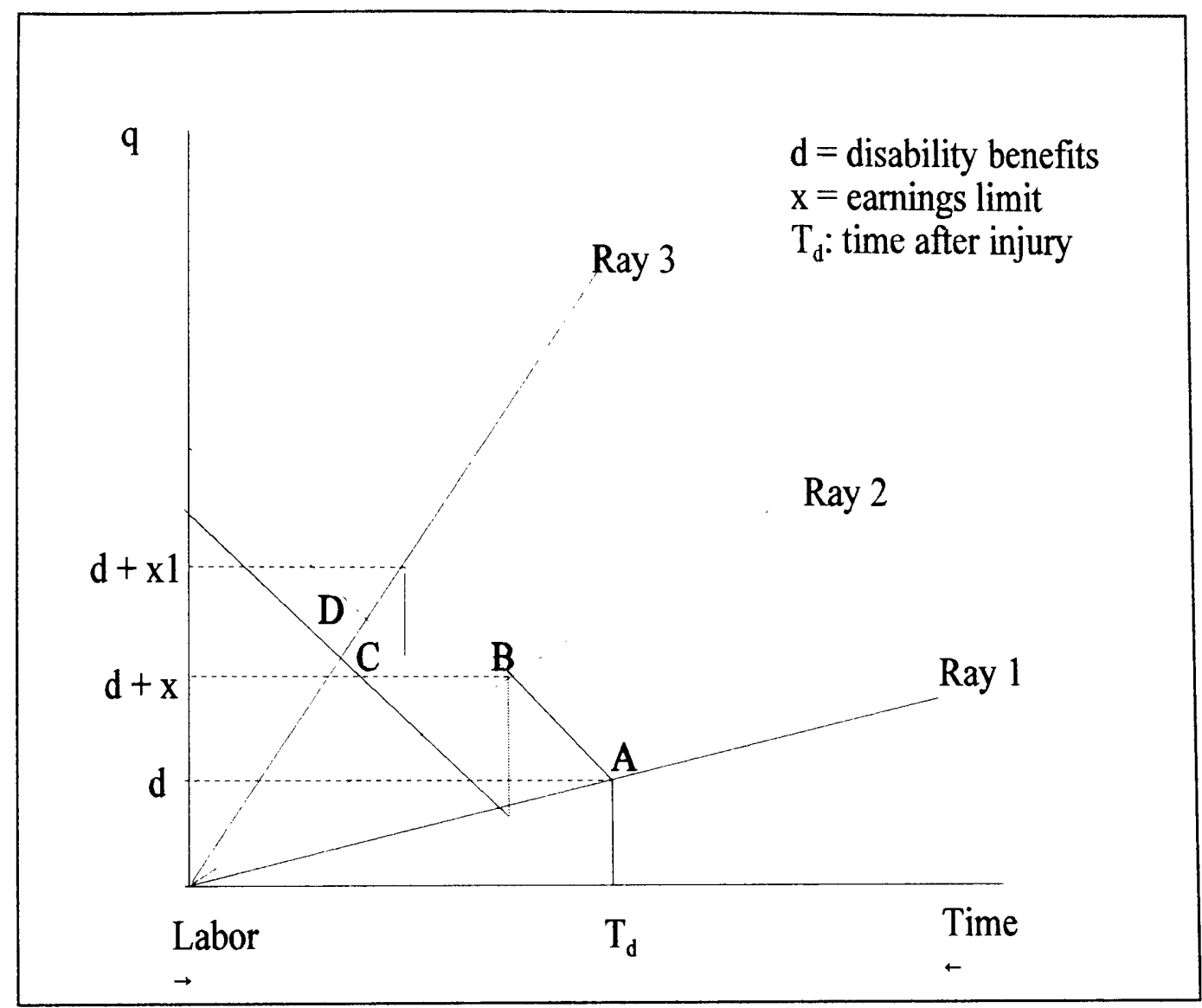

When the earnings limit increases, more people will choose to keep receiving benefits.

Previously an individual with preferences along Ray 3 would choose not to receive benefits, with the increased earnings limit this same individual will limit their earned income and keep receiving benefits. 
Figure 6: The Effect of Increasing Time on Labor Supplied

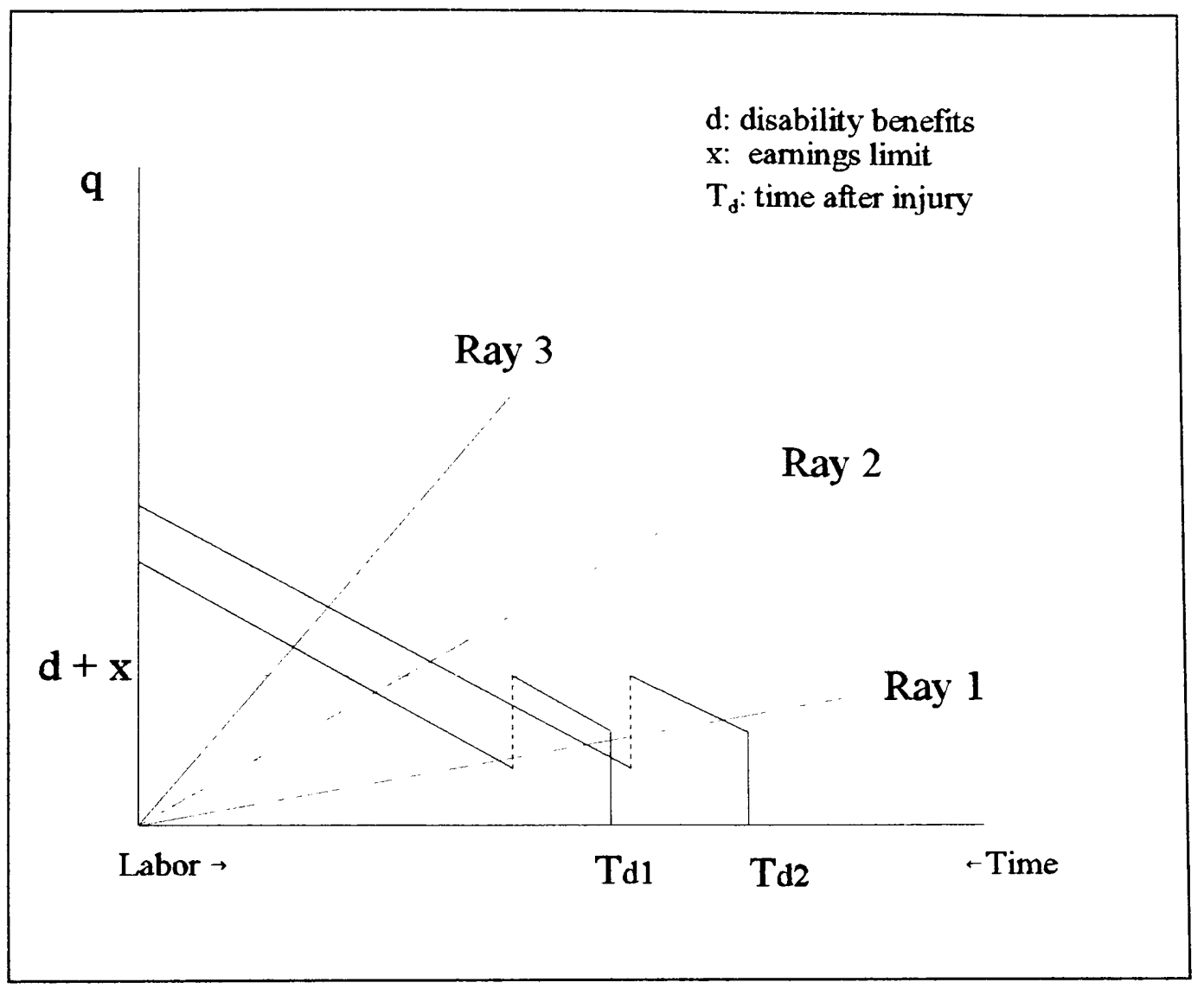

When the amount of time is increased, more people will participate in the labor force along every preference ray and both leisure and consumption will increase. Any policy that increases available time increases the amount of labor supplied, even without changing any policies regarding disability benefits. Government programs such as the Americans with Disabilities Act help to increase the time available by increasing society's accessibility. Rehabilitation programs also attempt to increase available time through teaching and therapy. 


\section{References:}

Acemoglu, Daron and Joshua Angrist. 1998. "Consequences of Employment Protection: The Case of the Americans with Disabilities Act” NBER Working Paper \# 6670

Baldwin, Marjoie and William G. Johnson. 2000. "Labor Market Discrimination Against Men with Disabilities in the Year of the ADA" Southern Economic Journal 66, 548-66

Bound, John and Timothy Waidman. 2000. "Accounting for Recent Declines in Employment Rates Among the Working-Aged Disabled” NBER Working Paper \#7975

Burkhauser, Richard V., J.S. Butler and Yang Woo Kim, 1995. "The Importance of Employer Accommodation on the Job Duration of Workers with Disabilities: A Hazard Approach"Labour Economics, 2, 109-130

Cardenas, Diane D. and Jason N. Doctor. 1998 "Cost-Effectiveness of Rehabilitation After Spinal Cord Injury" Critical Reviews in Physical and Rehabilitation Medicine" 10, 359-367

Conroy, L. and K. McKenna 1999. "Vocational Outcomes Following Spinal Cord Injury." Spinal Cord 37 624-633

Crisp, R., 1992 "Vocational Decision Making by Sixty Spinal Cord Injury Patients." Paraplegia 30 420-424

DipCot, R. Castle 1994. "An Investigation into the Employment and Occupation of Patients with a Spinal Cord Injury." Paraplegia 32 182-187

DeLeire, Thomas. 2000. "The Wage and Employment Effects of the Americans with Disabilities Act" Journal of Human Resources 35, 693-715

El Ghahit AZ and R.W. Hanson 1978. "Variables Associated With Obtaining and Sustaining Employment Among Spinal Cord Injured Males: a Follow-Up of 760 Veterans." Journal of Chronic Disabilities 31, 363-369

Engel, S., G.S. Murphy, J.A. Athanasou, L. Hickey 1998. "Employment Outcomes Following Spinal Cord Injury" International Journal of Rehabilitation Research 21 223-229

Frost, Frederick S. 1993. "Role of Rehabilitation After Spinal Cord Injury" Spinal Cord Injury $20, \# 3,549-559$

Hale, Thomas and Howard V. Hayghe, John M. McNeill. 1998. "Labor Market Activity, 1994" Monthly Labor Review, 121, 3-12

Haveman, Robert and Karen Holden, Barbara Wolfe, Paul Smith, Kathryn Wilson. 1999. "The Changing Economic Status of U.S. Disabled Men: Trends and Their Determinants, 1982-1991" Empirical Economics, 24, 571-598 
Haveman, Robert and Barbara Wolfe. 1990. "The Economic Well-Being of the Disabled, 19621984" Journal of Human Resources 25, 32-54

Hennessey, John 1996. “Job Patterns of Disabled Beneficiaries” Social Security Bulletin, 59

Hollenbeck, Kevin and Jean Kimmel 2001. "The Returns to Education and Basic Skills Training for Individuals with Poor Health or Disability" Upjohn Institute Staff Working Paper \# 01-72

Huettener, David A. and Anas F. Alhaiji 1998. "Economic Damages Due to Spinal Cord Injuries: Trends and Policy Implications." Journal of Forensic Economics 11(2), 121-126

Keller, Henry 1953, Rehabilitation of the Physically Handicapped, Colombia University Press, New York

Krause, Stuart. 1999. "Employment, SCI and Biographic Status" Archives of Physical Medicine and Rehabilitation 80 1494-1499

Krause, Stuart and Maya Sternberg, Joseph Maides, Sarah Lottes. 1998. "Employment after Spinal Cord Injury: Differences Related to Geographic Region, Gender and Race" Archives of Physical Medicine And Rehabilitation 79, 615-624

Krause, Stuart and Carol Anson. 1997. “ Adjustment After Spinal Cord Injury: Relationship To Participation in Employment or Educational Activities" Rehabilitation Counseling Bulletin 40, 202-214

Krause, Stuart and Carol Anson. 1997. "Self-perceived Reasons for Unemployment Cited by Persons With Spinal Cord Injury: Relationship to Gender, Race, Age, and Level of Injury" Rehabilitation Psychology

Krause, Stuart and Carol Anson. 1996. “Employment After Spinal Cord Injury: Relation to Selected Participant Characteristics" Archives of Physical Medicine and Rehabilitation" 77, 737-742

Krause, James S. 1992 "Employment After Spinal Cord Injury" Archives of Physical and Rehabilitation" 73, 163-169

Krueger, Alan and Douglas Kruse 1995. "Labor Market Effects of Spinal Cord Injuries in the Dawn of the Computer Age" NBER Working Paper \# 5302

McNeal, Donald R., Nancy J. Somerville, and Dorothy J. Wilson, 1999. "Work Problems and Accommodations Reported by Persons Who are Postpolio or Have a Spinal Cord Injury"Asssistive Technology 11 \#2 137-157

Murphy G. and D. Brown, J. Athanasou, P. Foreman, A. Young 1997. "Labour Force Participation and Employment among a Sample of Australian Patients with a Spinal Cord Injury." Spinal Cord 35 238-244 
Nakajima, A., and S. Honda. 1988. "Physical and Social Condition of Rehabilitated Spinal Cord Injury Patients in Japan: A Long-term Review." Paraplegia 26 165-176

Noreau, L., S.A. Dion, J. Vachon, M. Gervais, M.T. Laramee 1999. "Productivity Outcomes of Individuals with Spinal Cord Injuries" Spinal Cord 37 730-736

Oi, Walter 1991. "Disability and a Workfare-Welfare Dilemma" in Weaver op.cit

Rosen, Sherwin 1991. "Disability Accommodation and the Labor Market" Weaver op cit

Sioseen, A, C. Lundqvist, C. Blomstrand, L. Sullivan, M. Sullivan 1990. "The Quality of Life of Three Functional Spinal Cord Injury Subgroups in a Swedish Community" Paraplegia 28, 476-488

Tomassen, PCD., MWM Post, FWA van Asbeck 2000. "Return to Work After Spinal Cord Injury" Spinal Cord 38 51-55

Ville, I. And J.F. Ravaud 1996. "Work, Non-work, and Consequent Satisfaction after Spinal Cord Injury." International Journal of Rehabilitation Research 19 241-252

Weaver, Carolyn ed. 1991. Disability and Work: Incentives, Rights and Opportunities The American Institute Press, Washington D.C.

Witte, Ann Dryden, Magaly Queralt, Tasneem Chipty, Harriet Griesinger. 1998 "Unintended Consequences? Welfare Reform and the Working Poor" NBER Working paper 6798 
B.A. Economics and International Relations American University

Washington, District of Columbia

1988

M.A. Economics

Duke University

Durham, North Carolina

2000

ELA Scholar

Ethel Louise Armstrong Foundation

2002

Doctoral Candidate in Economics

Florida International University

Miami, Florida 